\title{
A Sea Ice Concentration Estimation Methodology Utilizing ICESat-2 Photon-Counting Laser Altimeter in the Arctic
}

\author{
Jun Liu ${ }^{1}$, Huan Xie ${ }^{2, *}$, Yalei Guo ${ }^{2}$, Xiaohua Tong ${ }^{2}$ and Peinan $\mathrm{Li}^{3}$ \\ 1 College of Urban Railway Transportation, Shanghai University of Engineering Science, \\ Shanghai 201620, China; junliurs@sues.edu.cn \\ 2 Shanghai Key Laboratory for Planetary Mapping and Remote Sensing for Deep Space Exploration, College of \\ Surveying and Geo-Informatics, Tongji University, Shanghai 200092, China; 1933665@tongji.edu.cn (Y.G.); \\ xhtong@tongii.edu.cn (X.T.) \\ 3 College of Environmental Science and Engineering, Donghua University, Shanghai 201620, China; \\ lipeinan@dhu.edu.cn \\ * Correspondence: huanxie@tongji.edu.cn
}

Citation: Liu, J.; Xie, H.; Guo, Y.;

Tong, X.; Li, P. A Sea Ice

Concentration Estimation

Methodology Utilizing ICESat-2

Photon-Counting Laser Altimeter in

the Arctic. Remote Sens. 2022, 14, 1130

https://doi.org/10.3390/rs14051130

Academic Editors: Xiao Cheng,

Yan Liu, Zhaohui Chi and Yi Luo

Received: 4 December 2021

Accepted: 22 February 2022

Published: 24 February 2022

Publisher's Note: MDPI stays neutral with regard to jurisdictional claims in published maps and institutional affiliations.

Copyright: (c) 2022 by the authors. Licensee MDPI, Basel, Switzerland. This article is an open access article distributed under the terms and conditions of the Creative Commons Attribution (CC BY) license (https:// creativecommons.org/licenses/by/ $4.0 /)$.

\begin{abstract}
NASA's Ice, Cloud and land Elevation Satellite-2 (ICESat-2) mission was launched in September 2018. The sole instrument onboard ICESat-2 is ATLAS, a highly precise laser that now provides routine, very-high-resolution, surface height measurements across the globe, including over the Arctic. To further improve the detection accuracy of the sea ice concentration (SIC), we demonstrate a new processing chain that can be used to convert the along-track sea ice freeboard products (ATL10) obtained by ICESat-2 into the SIC, with our initial efforts being focused on the Arctic. For this conversion, we primarily make use of the classification results from the type (sea ice or lead) and segment length data gathered from ATL10. The along-track SIC is the ratio of the area that is covered by sea ice segments to the area of all of the along-track segments. We generated a monthly gridded SIC product with a $25 \mathrm{~km}$ resolution and compared this to the NSIDC Climate Data Record (CDR) sea ice concentration. The highest correlation was determined to be 0.7690 in September at high latitudes and the lowest correlation was found to be 0.8595 in June at mid-latitudes. The regions with large standard deviations in summer and autumn are mainly distributed in the thin-ice areas at mid-latitudes. In the Laptev Sea and Kara Sea of east Siberia, the differences in the standard deviation were large; the maximum bias was -0.1566 , in November, and the minimum bias was -0.0216 , in June. ICESat-2 shows great potential for the accurate estimation of the SIC.
\end{abstract}

Keywords: arctic; ICESat-2; sea ice concentration; polar oceans; lidars

\section{Introduction}

Spatial-temporal changes in sea ice extent are sensitive indicators of climate change. The sea ice concentration (SIC) is an important parameter for the study of sea ice changes. The SIC represents the density of the sea ice in space and refers to the ratios of ice-covered areas to the total unit area. From this definition, it follows that the SIC depends on the measurement resolution. The SIC estimations are a powerful tool that can be used for research and predictions focusing on sea ice changes and for the analysis of the interaction between sea ice and seawater, providing an opportunity for the exploration and development of Arctic energy and for the opening of Arctic waterways; this has become a strategic goal of some countries [1-5].

Due to the high spatial and temporal coverage of polar regions, polar-orbiting satellites have been key to observing changes in Arctic sea ice. Currently, visible near-infrared and active or passive microwave remote sensing (especially passive microwave remote sensing; PM) are commonly used to monitor the SIC [6-9]. Optical images can provide information on sea ice coverage and area. These images are highly affected by clouds and nights and polar nights exist in the polar regions. Therefore, this method is suitable for small areas 
with clear skies and areas that do not experience polar night periods. Conventional SAR systems can distinguish between open water and different ice types with high resolution through the application of different parameters, such as radar backscattering. However, the radar backscattering coefficients of sea ice and open water might vary significantly under different environmental conditions, indicating the need for additional information (e.g., polarimetry) for improved ice monitoring [10]. Since the launch of the Scanning Multichannel Microwave Radiometer (SMMR) in 1978, continuous observation data have been available, creating the advantages of large coverage and a short re-entry period. Passive microwave remote sensing data have become the main data source for longterm series and large-scale research on polar sea ice [11]. The main algorithms for SIC inversion using microwave radiometer brightness temperature data include the bootstrap (BT) algorithm and the NASA team (NT) algorithm developed by the NASA Goddard Space Flight Center [12]. The European Organization for the Exploitation of Meteorological Satellites (EUMETSAT) has released quasi-real-time SIC data called OSI-SAF. The OSI SAF algorithm combines the Bristol algorithm and the bootstrap (BT) algorithm. How to interpret the mixed sea ice and seawater pixels is the key for the application of passive microwave remote-sensing technology [13-19].

Radar altimeters measure the heights to the bottom of a snow layer. Some scholars use the ERS-1(a radar) echo waveform data (ERS.ALT WAP) to determine the SIC [20]. The basic algorithm judges whether the illuminated area is sea ice or seawater based on the echo waveforms that are collected along the track. By gridding the study area to a certain scale, each grid can be roughly covered by the radar's illuminated area, so that the SIC of the sea area can be calculated. The techniques used to date to estimate the SIC have some limitations, such as the influence of the atmosphere, the physical temperature of the ice and the presence of snow and melt [21]. ICESat-2 was launched by National Aeronautics and Space Administration (NASA) in September 2018 to probe the Earth's surface with three pairs of laser beams. ICESat-2 utilizes photon-counting techniques to achieve higher spatial resolutions and it is expected that this will improve the accuracy of SIC detection and that it will allow us to explore new data sources as useful complements to optical imaging [22]. However, no SIC products have been estimated using IS-2 data as of yet.

Therefore, this study proposes a method that can be implemented to obtain the SIC based on ICESat-2 using the ATL10 sea ice freeboard products and compares and evaluates these new SIC estimates with National Snow and Ice Data Center's (NSIDC) CDR SIC products. In the following sections, we describe the ATL10 freeboard data, the NSIDC/CDR SIC data that are utilized here (Section 2) and the approach that we used to estimate the SIC (Section 3). We demonstrate the production of gridded fields to obtain sea ice concentration data, highlight the regional and seasonal variability in these fields and make a comparison with coincident estimates obtained from the NSIDC/CDR SIC data (Section 4). We draw our conclusions in Section 5.

\section{Data}

\subsection{ICESat-2 ATLAS/ATL10 Sea Ice Freeboard Data from the Arctic}

The laser altimeter that is onboard ICESat-2 is known as the photon-counting Advanced Topographic Laser Altimeter System (ATLAS) [23]. The time tags of detected single-photon events are recorded based on the time-of-flight ranging principle. The laser emission frequency is $10 \mathrm{kHz}$. Each pair of beams contains a strong beam and a weak beam. According to the satellite orbit height and satellite motion speed of ICESat-2, laser footprints that are about $13 \mathrm{~m}$ in size are created on the Earth's surface, each of which are located $0.7 \mathrm{~m}$ apart. The vertical orbit distance of each pair of beams is about $3.3 \mathrm{~km}$ and the vertical orbit distance between the strong and weak beams in each pair of beams is about $90 \mathrm{~m}$ [24].

We used the ICESat-2 ATL10 sea ice freeboard products (Release 003), which are available to the public through NSIDC [25]. ICESat-2 has 21 standard data products that are divided into three levels, namely, ATL01 ATL21. ATL10 uses all of the available sea 
surface height measurements to estimate the sea ice freeboard at a specific spatial scale, including the estimation of statistics regarding sea surface and sea ice height. The data are stored in the H5 file format [26-30]. The ATL10 products provide freeboard estimates within $10 \mathrm{~km}$ segments that include at least one sea surface reference. The local sea surface reference height(h_ref) is from available lead(s) within a $10 \mathrm{~km}$ segment and each lead may contain one or more consecutive sea surface height segments (SSHseg). The freeboard height ( $\mathrm{h} \_\mathrm{f}$ ) is calculated as the difference between the surface height $\left(\mathrm{h} \_\mathrm{s}\right)$ and the local sea surface reference (i.e., $\left.h \_f=h \_s-h \_r e f\right)$. In ATL10, the freeboard is only provided if the SIC is above $50 \%$ and if the height of the sample is at least $50 \mathrm{~km}$ from the coast (to avoid uncertainty in coastal tide correction). More details on the sea ice algorithms can be found in [30]. Based on the work in [31], the freeboard height of IS-2 was assessed first.

For sea ice profiling, individual segment heights are produced from each beam using 150-photon aggregates in an effort to produce the heights, as described in the ATL07 sea ice/sea surface height product description and Algorithm Theoretical Basis Document. The IS-2 ATL03 photon datasets, as well as the ATL07 and ATL10 freeboard data, are shown in Figure 1. The ATL07 removes the mean sea surface (MSS) heights, which are bilinearly interpolated to the photon locations.

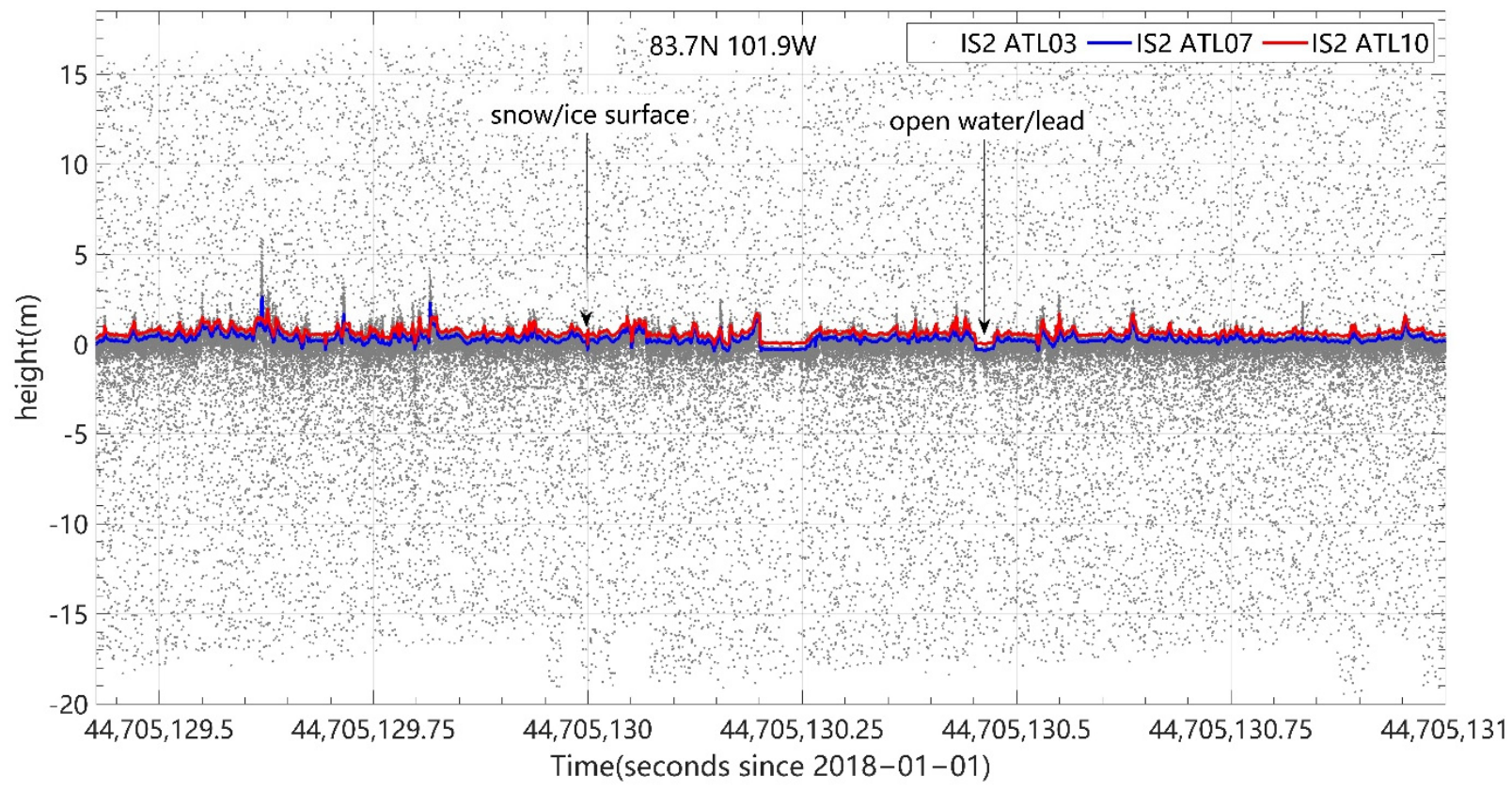

Figure 1. Profile of ATL03 photons (gray dots) from the strong Beam 6 (gt1l in this orbit cycle). These data were collected on 2 June 2019; along-track surface height profiles from ATL07 (blue line) and ATL10 freeboard data (red line) for a small $(\sim 1 \mathrm{~km})$ profile (location in $83.7 \mathrm{~N}, 101.9 \mathrm{~W}$ ).

\subsection{National Snow and Ice Data Center CDR Sea Ice Concentration Data}

We compared our IS-2 SIC with the NSIDC/CDR SIC estimated from an SSMIS (Special Sensor Microwave Imager Sounder) mounted on DMSP-F17 (Defense Meteorological Satellite Program). We used the ATL10 data from 1 January 2019 to 31 December 2019 and selected the CDR SIC data from the same period for a comparative analysis. Near-real-time daily data from CDR version 4 were obtained from NSIDC. These data comprise polar stereographic projections with a grid cell size of $25 \times 25 \mathrm{~km}$. The principle of the inversion algorithm is to use the relationship between the brightness temperature value and the polarization mode of different sea ice types in different microwave channels. The CDR was generated using an algorithm that was derived by combing the NASA Team and bootstrap algorithms [32,33]. Table 1 presents the parameter comparison between SSMIS and ATLAS. 
Table 1. Comparison of parameters between SSMIS and ATLAS.

\begin{tabular}{ccc}
\hline Product & IS2-SIC & NSIDC/CDR SIC \\
\hline Instrument & ATLAS & SMMR, SSM/I, SSMIS \\
Satellite & ICESat-2 & DMSP-17 \\
Start time & 15 September 2018 & 1 November 1978 \\
Inclination angle $\left({ }^{\circ}\right)$ & 92 & 98.8 \\
Operational altitude, $\mathrm{R}(\mathrm{km})$ & 496 & 833 \\
Swath width $(\mathrm{km})$ & 6 & 1394 \\
Footprint & $\sim 13 \mathrm{~m}$ & $15 \mathrm{~km} \times 13 \mathrm{~km}$ \\
\hline
\end{tabular}

\section{Methods}

\subsection{Sea Ice Concentration Processing Using ICESat-2 Data (IS2-SIC)}

The ICESat-2 ATL10 freeboard dataset for the Arctic was preprocessed to obtain the longitude, latitude, delta time and segment length. After preprocessing the ATL10 data, the time resolution was set to one month and the spatial resolution was set as a $25 \mathrm{~km}$ grid. Polar stereographic projection was used and the data were calculated by grid. We used the classification results from the ATL10 products to determine the type (sea ice or lead). The coverage area of the segment, which is the area of a circle whose diameter is the segment length, needed to be calculated. The number of tracks, the number of segments and the segment distribution in each grid affect the SIC estimation accuracy. When the segments are uniformly distributed within the grid, it can be assumed that the along-track SIC in the grid is equal to the actual SIC of that grid. The along-track SIC is the ratio of the area that is covered by sea ice segments to the area of all of the along-track segments. Segments that are only distributed on a small part of the grid cannot be representative of the whole grid due to severe data scarcity. If the latitude difference between the segments in the grid is less than 0.1 degrees, or if there are no segments in the grid, then we do not calculate the SIC for that grid. A schematic of the method that was used in this study is shown in Figure 2. This method mainly included the steps below.
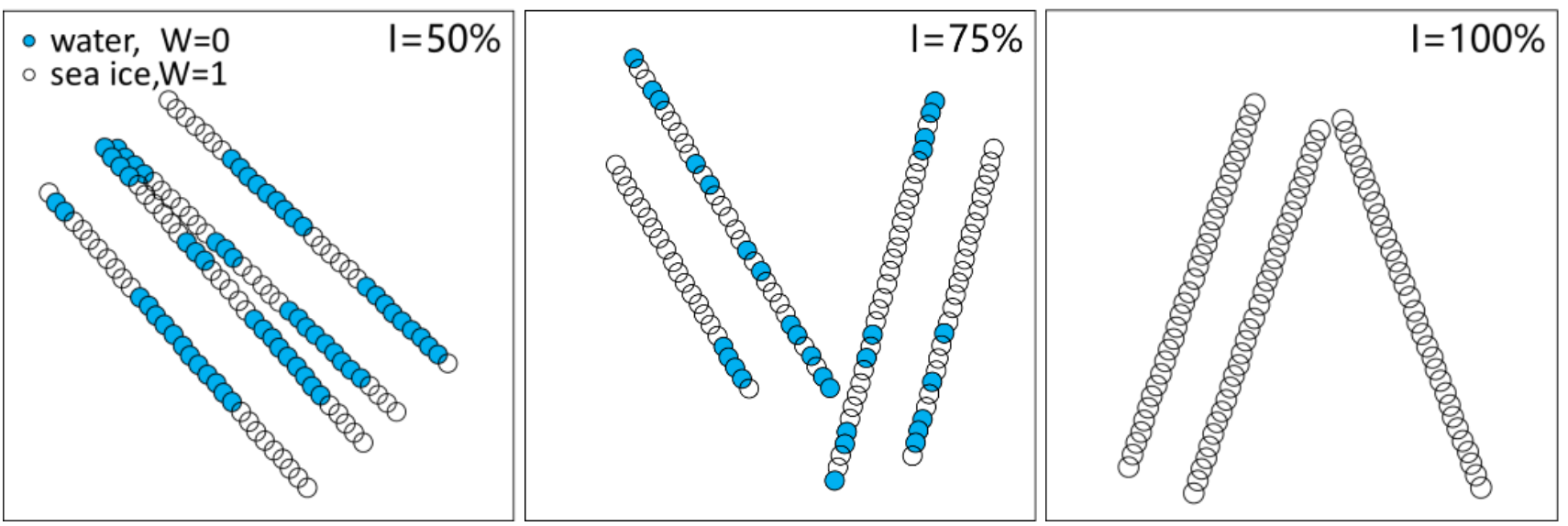

Figure 2. Schematic of the method used in this study to derive the sea ice concentration. The blue points indicate that the segment surface type is leads; the white points indicate that the segment surface type is sea ice. I denotes the SIC of the grid.

First, we extracted the longitude, latitude, delta time, segment surface type, segment length and Spacecraft Orientation parameters from the ATL10 freeboard data. The parameters used in the present study are summarized in Table 2. 
Table 2. ATL10 parameters used in the paper.

\begin{tabular}{|c|c|c|}
\hline Parameter Name & Description & Parameters of the Source \\
\hline Latitude & Lat of segment center & $\begin{array}{l}\text { ATL10/gtx/freeboard_beam_seg- } \\
\text { ment/height_segments/latitude }\end{array}$ \\
\hline Longitude & Lon of segment center & $\begin{array}{l}\text { ATL10/gtx/freeboard_beam_seg- } \\
\text { ment/height_segments/longitude }\end{array}$ \\
\hline delta_time & $\begin{array}{l}\text { Number of GPS seconds since } \\
\text { the ATLAS SDP epoch. }\end{array}$ & $\begin{array}{l}\text { ATL10/gtx/freeboard_beam_seg- } \\
\text { ment/height_segments/delta_time }\end{array}$ \\
\hline Segment surface type & $\begin{array}{l}\text { Segment surface type: sea ice or different } \\
\text { sea surface types, with } 0 \text {, cloud-covered; } \\
1 \text {, all other segments are non-lead snow/ } \\
\text { ice surfaces; } 2 \sim 9 \text {, lead. }\end{array}$ & $\begin{array}{l}\text { ATL10/gtx/freeboard_beam_seg- } \\
\text { ment/height_segments/height_segment_type }\end{array}$ \\
\hline Length of segment & $\begin{array}{l}\text { Along-track length of segment containing } \\
\text { n_photons_actual ATL07 length_seg) }\end{array}$ & $\begin{array}{l}\text { ATL10/gtx/freeboard_beam_seg- } \\
\text { ment/height_segments/height_segment_length_seg }\end{array}$ \\
\hline Spacecraft Orientation & $\begin{array}{l}\text { This parameter tracks the spacecraft } \\
\text { orientation between the forward, backward } \\
\text { and transitional flight modes. }\end{array}$ & ATL10/orbit_info/sc_orient \\
\hline
\end{tabular}

We used the strong beams (Beam 11, 2 l and 3l) to calculate the SIC. In this paper, the flight direction parameter sc_orient was used to judge the strong and weak beams. This parameter tracks the direction of the spacecraft between forward flight mode, backward flight mode and transition flight mode. Its values are 0,1 and 2 . When the strong beam guides the weak beam, the backward flight mode is being used, sc_orient $=0$ and the strong beam is on the left. When the weak beam guides the strong beam, ICESat-2 flies forward, sc_orient = 1 and the strong beam is on the right. ICESat- 2 is considered to be in a transitional state when it is moving between the two directions; in this case, sc_orient $=2$ and the data quality may deteriorate during the transition process. The segment length of the strong beam ranges from $10 \mathrm{~m}$ to $200 \mathrm{~m}$ (average of $15 \mathrm{~m}$ ) and the segment length of the weak beam ranges from $40 \mathrm{~m}$ to $800 \mathrm{~m}$ (average of $60 \mathrm{~m}$ ). When calculating the spatial resolution of the segments, the segment length of a single laser footprint is $14 \mathrm{~m}$; that is, the average segment length of strong beam ranges is $\sim 30 \mathrm{~m}$ and that of the weak beam is $\sim 75 \mathrm{~m}$. Based on the value of the flight direction parameter, the strong beam in ATL10 was retained. Only the strong beam was used in the subsequent calculations, as it provides higher along-track resolutions than the weak beams due to their smaller segment length, improving the calculation accuracy.

Second, the spatial distribution of the SIC varies with the climate temperature, so we divided the ATL10 by month according to the delta_time and calculated the SIC for different months. For the monthly ATL10, we applied the monthly ATL10 data to the NSIDC $25 \times 25 \mathrm{~km}$ polar stereographic grid according to the latitude and longitude information in order for it to be consistent with the international products. The coordinate origin was located at the North Pole, the standard latitude line was $70 \mathrm{~N}$ and the grid included 304 columns and 448 rows. The longitude and latitude corresponding to each grid were provided by the NSIDC website (https: / / nsidc.org/data/polar-stereo/ps_grids.html, accessed on 1 December 2021).

The SIC of each grid in different months could be calculated for each monthly gridded ATL10, such as the SIC of the October grid. The SIC of a grid $I$ is equal to the sea ice area in the grid divided by the area of the grid, which can be calculated as follows:

$$
I=\frac{S_{I}}{S} \times 100 \%
$$

where $S_{I}$ is the sea ice area in the grid and $S$ is the area of the grid. When the segments are uniformly distributed within the grid, it is assumed that the SIC of the grid $I$ is equal to the 
along-track SIC. The along-track SIC $I_{\text {track }}$ can be obtained based on the ATL10 freeboard data. Based on Equation (1), the formula to calculate the along-track SIC $I_{\text {track }}$ in the grid is

$$
\begin{gathered}
I_{\text {track }}=S_{I_{-} \text {track }} / S_{\text {track }} \\
S_{I_{-} \text {track }}=\sum_{i=1}^{N} \sum_{j=1}^{P_{i}} \pi\left(L_{i j} / 2\right)^{2} \cdot k \cdot W_{i j} \\
S_{\text {track }}=\sum_{i=1}^{N} \sum_{j=1}^{P_{i}} \pi\left(L_{i j} / 2\right)^{2} k
\end{gathered}
$$

where $S_{I_{-} \text {track }}$ is the area of along-track sea ice, $S_{\text {track }}$ is the along-track area, $N$ is the number of tracks in the grid, $P_{i}$ is the number of segments along the track $i$ in the grid and $\varphi_{i j}$ is the latitude. $L_{i j}$ is the segment length, so the segment-covered area can be calculated as a circle with a diameter of $\pi\left(L_{i j} / 2\right)^{2} . W_{i j}$ is the surface type of the segment, where 1 indicates an ice/snow surface and 0 indicates a non-snow/ice surface. The segment surface type can be obtained from the parameter seg_surf_type (Table 2). $k$ is the projection deformation factor in the latitude direction and we use the polar stereographic projection $k=\cos \varphi_{i j}$.

The SIC for each grid needs to be calculated separately to determine the monthly gridded SIC products. Substitute $S_{I_{-} \text {track }}$ and $S_{\text {track }}$ in Formula (1) as $S_{I}$ and $S$, respectively. According to the assumptions, $I=I_{\text {track }}$. When all of the segments in the grid have iceand snow-covered surfaces, $S_{I_{-} \text {track }}=S_{\text {track}}$, then $I=1$; when all segments are leads, $S_{I_{-} \text {track }}=0$ and $I=0$. The actual situation is somewhere in between, where the range of $I$ is $(0,1)$. The ICESat-2 SIC processing algorithm is shown in Figure 3.

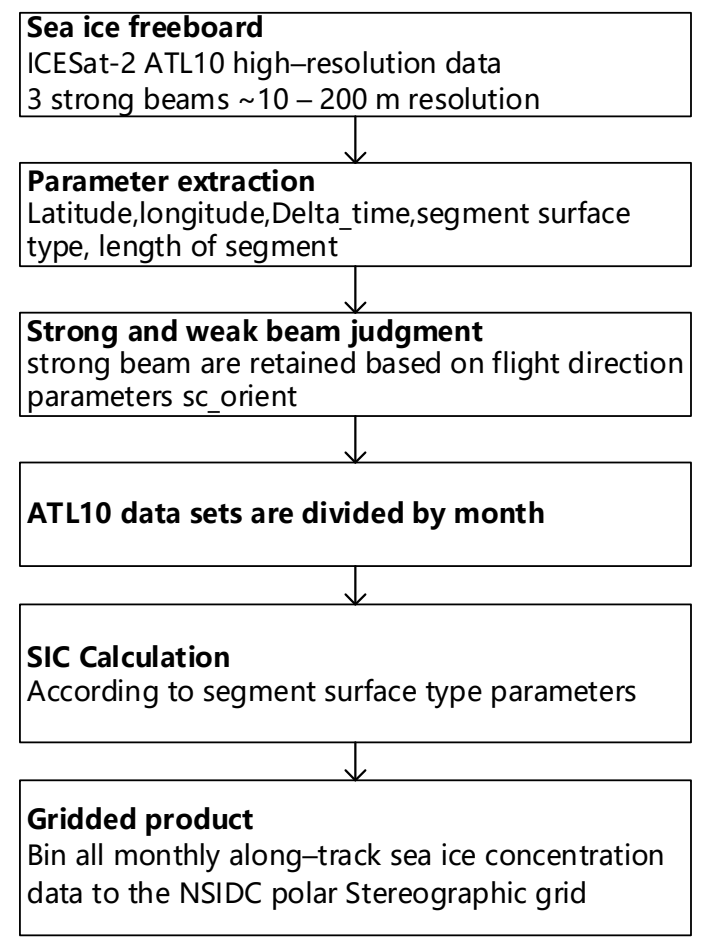

Figure 3. ICESat-2 sea-ice-concentration processing algorithm.

The ATL10 along-track height segments overlap with each other over at least half of the length of the segment. To analyze the effect of segment overlapping on the results, we used three methods to calculate the sea ice concentration and a diagram representing the segment overlap area is shown in Figure 4. 


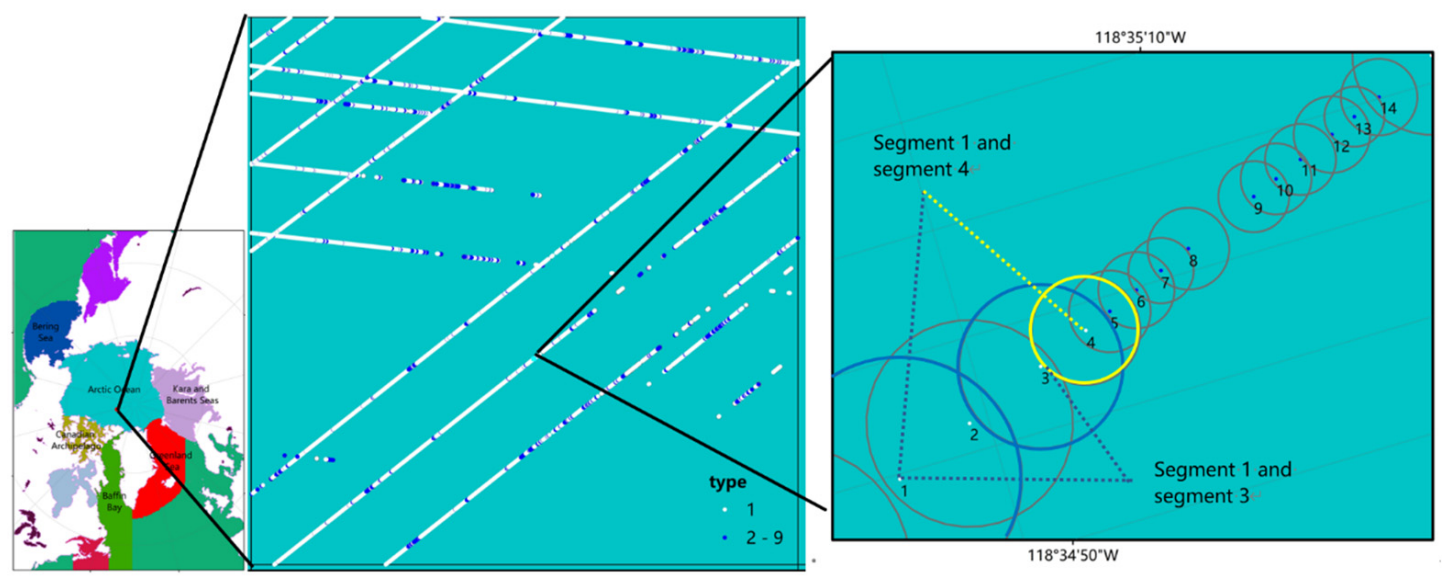

Figure 4. Segment overlap area diagram. Selected grid location in the Arctic Ocean (left); in this grid (middle), all of the segments with white dots represent a sea ice segment and blue dots represent lead; several segment areas are shown to overlap in the grid (right).

A. Use all of the segments within the grid with approximately $50 \%$ overlap (e.g., segment 1 and segment 2). The SIC is 0.79263 . The selected grid has 14 tracks and 19,394 segments, including 16,695 sea ice segments.

B. Take a segment at an interval (e.g., segment 1 and segment 3 ) where only half of the data are used and where there is a small overlap of about $5 \%$ between the segments. There are 9698 segments (including 8349 sea ice segments) and the SIC is 0.79261.

C. Take a segment at two intervals (e.g., segment 1 and segment 4 ) and use $1 / 3$ of the data. The segments do not overlap at all. There are 6464 segments (including 5558 sea ice segments) and the SIC is 0.79255 .

The areas of the segments overlap and when the ratio of the sea ice area to the total area is calculated, they cancel each other out. Therefore, the differences in the SIC grid estimated by these three methods are small and the differences begin to differ from the fourth decimal place onwards. Therefore, in order to make full use of the observed data, we used all of the segments to calculate the SIC.

\subsection{Comparative Evaluation Index}

Through the above steps, the monthly gridded SIC products were obtained. The IS-2 SIC can be assessed in comparison with the NSIDC/CDR SIC by using the mean bias, root-mean-squared error (RMSE) and correlation coefficient (r). In a unified coordinate grid, according to the latitude and longitude of the center location of the grid, the grid corresponding to the relationship between the ICESat-2 products and NSIDC/CDR products with a $25 \mathrm{~km}$ resolution was found. The mean bias and RMSE can be expressed as

$$
\begin{gathered}
\text { Bias }=\frac{\sum_{j=1}^{n}\left(I_{j}-N_{j}\right)}{n} \\
\text { RMSE }=\sqrt{\frac{\sum_{j=1}^{n}\left(I_{j}-N_{j}\right)^{2}}{n}}
\end{gathered}
$$

where $I_{j}$ is the monthly gridded ICESat-2 SIC; $N_{j}$ is the monthly gridded NSIDC/CDR $\mathrm{SIC} ; j$ is the serial number of the grid; and $n$ is the total number of matching grids in the sea ice area.

$$
r=\frac{E\left(\left(I_{j}-\mu_{I S-2}\right)\left(N_{j}-\mu_{N}\right)\right)}{\sigma_{I S-2} \sigma_{N}}
$$


where $\sigma_{I S-2}$ and $\sigma_{N}$ represent the standard deviation of the ICESat-2 SIC and NSIDC/CDR SIC and $\mu_{I S-2}$ and $\mu_{N}$ represent the average values of ICESat- 2 SIC and NSIDC/CDR SIC, respectively.

\section{Results and Discussion}

In this study, monthly gridded SIC products were obtained using ICESat-2 ATL10 data for the entire Arctic for the entirety of the year 2019. The spatial distribution characteristics and time change characteristics were analyzed and the validation data were selected from the NSIDC/CDR SIC products. To ensure the reliability of the analysis results, potential outliers needed to be filtered out based on the three-sigma rule.

We analyzed the results obtained in the Central Arctic, Beaufort Sea, Chukchi Sea, East Siberian Sea, Laptev Sea, Kara and Barents Sea, Greenland Sea, Baffin Bay Sea, Bering Sea and Canadian Archipelago. The "Arctic Ocean" domain includes the Central Arctic, Beaufort Sea, Chukchi Sea, East Siberian Sea and Laptev Sea. A map of these regions is shown in Figure 5.

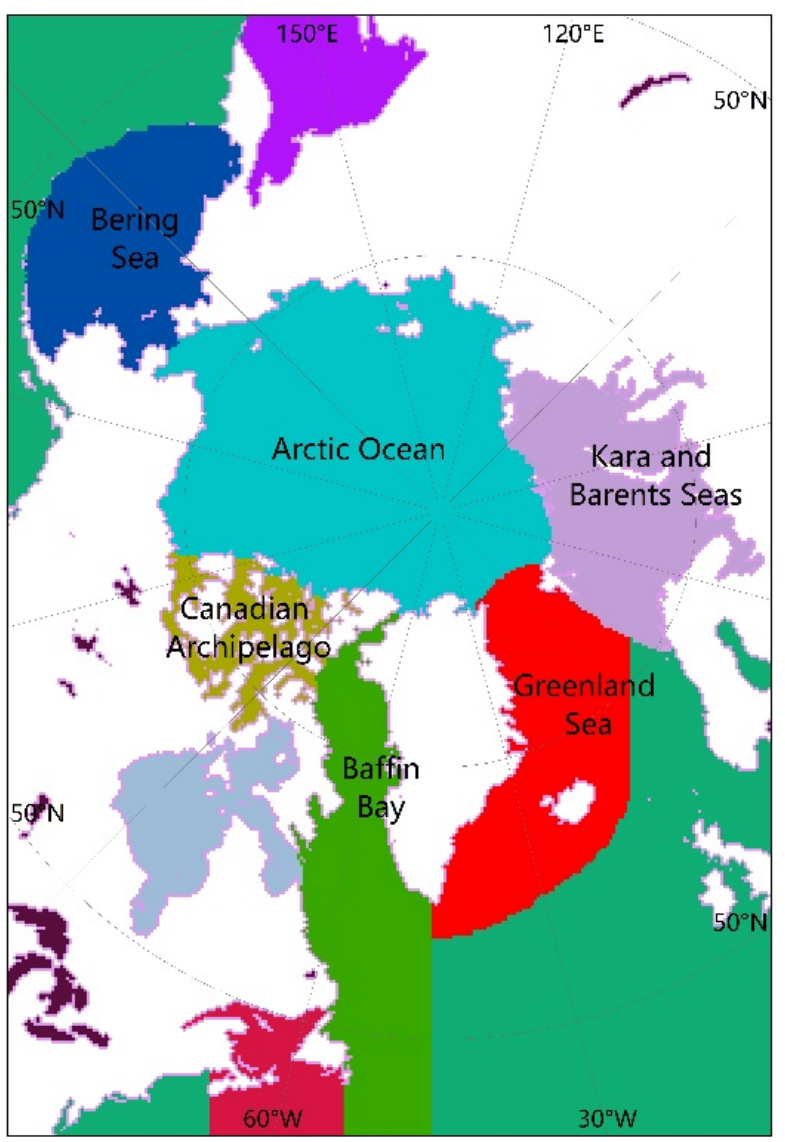

Figure 5. Map of the Arctic highlighting the various study regions analyzed: Arctic Ocean (Central Arctic, Beaufort Sea, Chukchi Sea, East Siberian Sea and Laptev Sea); Kara and Barents Seas; Greenland Sea; Baffin Bay Sea; Bering Sea; Canadian Archipelago.

\subsection{Spatial Variability in Sea Ice Concentration}

The monthly maps of our SIC estimates from three strong beams for 2019 in the entire Arctic are shown in Figure 6. Due to a spacecraft anomaly, there was an observation gap between 26 June and 26 July 2019. 

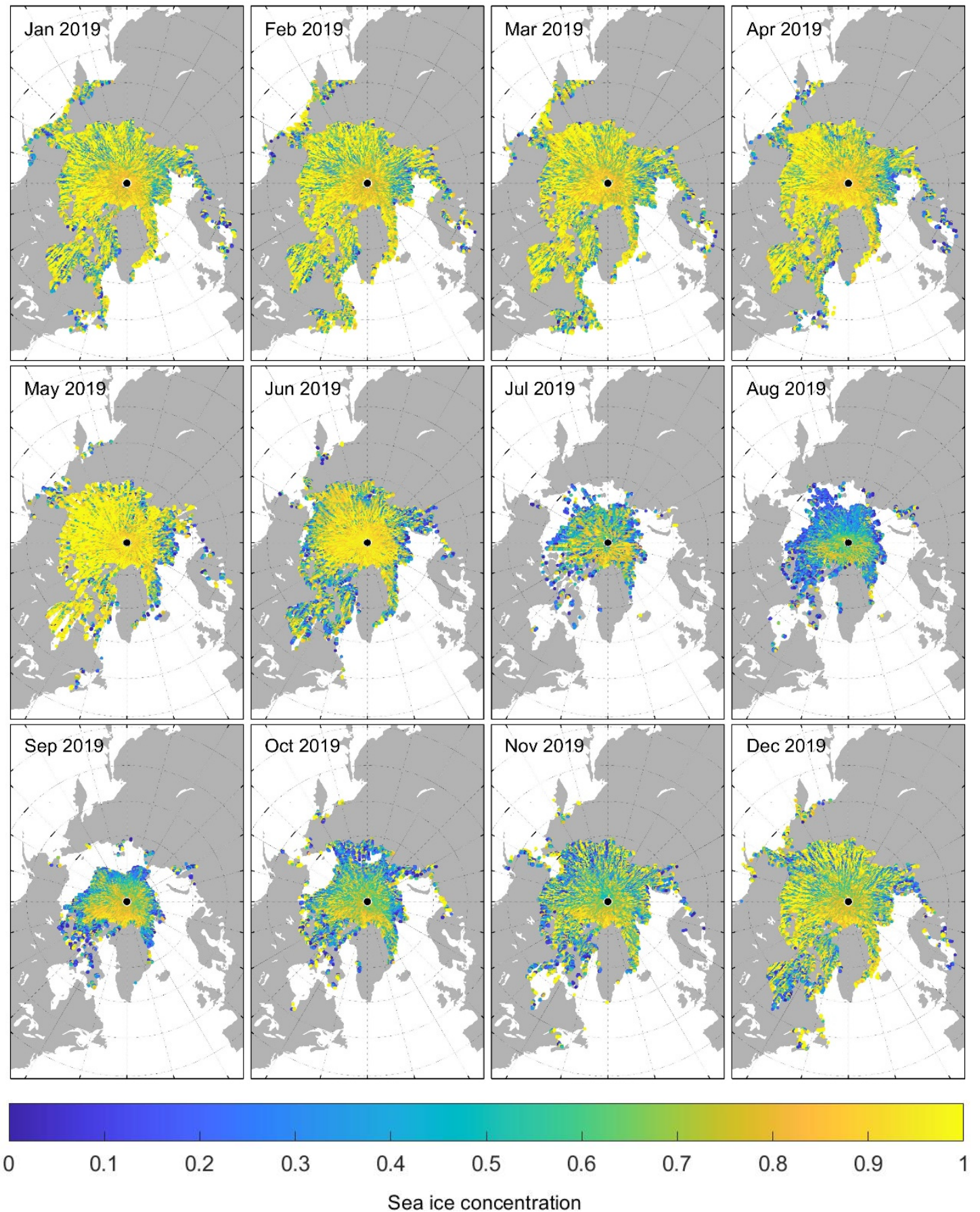

Figure 6. Monthly (from January to December) sea ice concentration from ICESat-2.

Across all months, the SIC showed a general increase toward the coastlines of Greenland and the Canadian Archipelago, which is the region where ice convergence is often observed and where there is consistently older ice and snow [34,35]. Our estimates of the spatial variability in the SIC are entirely reasonable. The SIC of the newly formed first year ice (FYI) region in the Beaufort/Chukchi Sea and the eastern part of the Arctic Ocean was less than 0.7 0.8 and the SIC of the older and deformed multiyear ice (MYI) region in the Central Arctic was about $0.9 \sim 1$.

Maximum Arctic Sea ice coverage occurred in March; the minimum was observed in September and it was stable in March and April. The glacial period spans from October to March and the melting period is from May to September. During the melting period (from May to September), the ice-covered area was smaller than it was during the freezing period 
(from October to March). The area that was covered by the MYI was relatively stable. After the summer melt, the FYI only accounted for about $10 \%$ of the area and the MYI accounted for the majority of the area in September. The observational gap caused by the spacecraft anomaly may result in smaller sea ice coverage being observed in July compared to August.

In October, late sea ice freeze-up was observed across the East Siberian Sea region (location circled in red). In November, there was an increase in the ice coverage toward the southern Arctic peripheral seas, including in the Chukchi Sea, East Siberian Sea, Laptev Sea, Kara Sea and Baffin Bay, indicating the formation of relatively new ice. November was the month where thin, young ice showed its maximum extension; this was especially the case through the Beaufort Sea since the ice in the Laptev and Kara seas remains thin throughout winter (from 1 December to 30 February) [36]. In December, the coverage extended through the Bering Strait and Canadian Archipelago. December showed a higher SIC through the southern Beaufort Sea, which is likely due to the anticyclonic drift of the Beaufort Gyre driving the import of older ice from the Central Arctic [37,38]. In January, the ice extended further south, including the ice in the Bering Sea. In Section 4.2, we show binned SIC estimates, which enabled us to produce monthly differences and to estimate the spatial patterns of the changes in the seasonal SIC more quantitatively.

\subsection{Sea Ice Concentration and the Number of Tracks in Grid Distributions}

In this section, we calculated the seasonal evolution of the monthly number of tracks in the grid and the SIC distribution in the Arctic for 2019, which is shown in Figure 7. Maps of the Arctic region are provided in Figure 5. The mean monthly SIC values increased from 0.74 to 0.82 (from January to May) and then began to decrease to 0.47 , which was the minimum value in August, before they finally increased to 0.68. The SIC distribution showed a unimodal distribution from June to November and monotonic increases in January, February, March, April, May and December. Initially, the SIC showed a unimodal distribution from early spring (June) to the end of fall (November) and the bimodal distribution curve in August was flat. The Arctic is dominated by the MYI. The SIC distribution increased monotonically in winter.
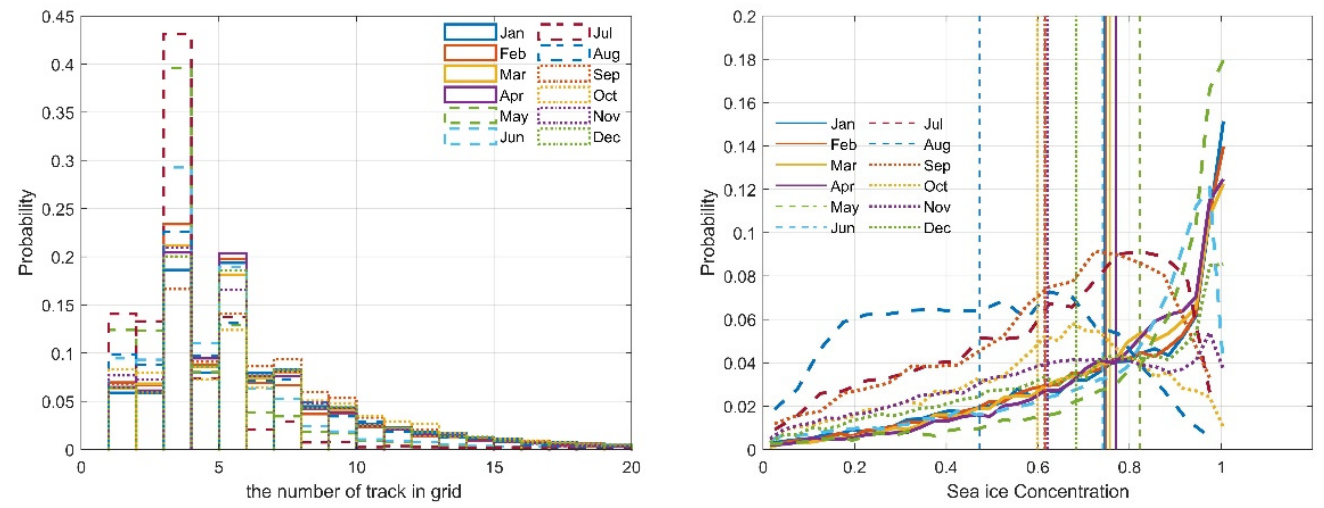

Figure 7. Monthly (from January to December) histograms of the number of tracks in the grid (left) and the sea ice concentration within this Arctic domain (right). The lines are plotted through the bin centers of the underlying histogram values using a bin width of 0.03 . The vertical lines show the mean monthly values for all data within this Arctic domain.

The seasonal evolution of the regional SIC distributions across all six of our Arctic study regions is shown in Figure 8. The Arctic Ocean includes the Central Arctic, Beaufort, Chukchi, E. Siberian and Laptev regions. The MYI in the Central Arctic region was thicker than it was in all of the regions and we saw in this more reduced Arctic domains than in the all-Arctic region. A gradual monotonic increase in the sea ice thickness could be observed from January to May. The Arctic Ocean region had the greatest sea ice thickness among all of the regions. The SIC distribution from January to June showed a monotonically increasing distribution curve, with an average SIC of 0.84 and a maximum mean SIC value 
of 0.90 in May. The mean value started to decrease in June and the lowest mean SIC dropped to 0.49 in August, decreasing by about 0.40 . The curve increased monotonically from June to November and, from October to December, the SIC distribution showed another gradual monotonic increasing trend (the mean SIC was 0.62 in October, 0.63 in November and 0.73 in December).
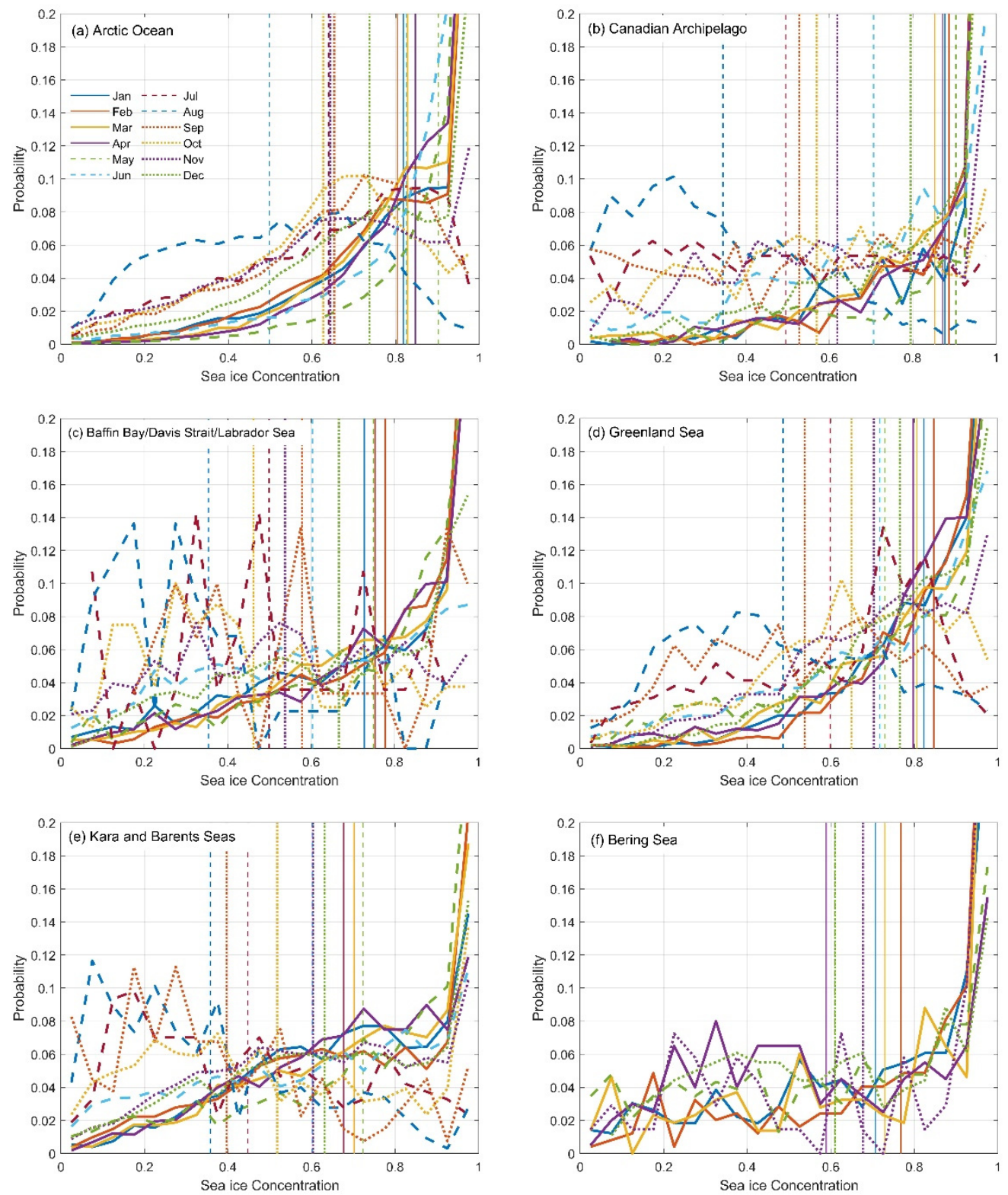

Figure 8. Monthly (from January to December in 2019) histograms of the regional sea ice concentration. The Arctic Ocean includes the Central Arctic, Beaufort, Chukchi, E. Siberian and Laptev regions: (a) Arctic Ocean; (b) Canadian Archipelago; (c) Baffin Bay; (d) Greenland Sea; (e) Kara and Barents Seas; (f) Bering Sea. The lines are plotted through the bin centers of the underlying histogram values using a bin width of 0.03 . The dashed lines show the mean monthly values for all data within this Arctic domain. The $\mathrm{Y}$ axis is unified to $0 \sim 0.2$.

The SIC in the Canadian Archipelago Sea was 0.88 in January; it began to decrease in June, reached a minimum of 0.34 in August and then gradually increased and rose to 0.79 in December. The SIC fluctuated greatly. This is because thinner FYI grows faster. There was no sea ice cover in the Kara Sea from July to October, but the sea ice cover increased from November to December and, from January to June, the SIC increased gradually. The 
Barents Sea was largely free of sea ice throughout the year. The initial decline in the SIC in the Barents and Kara Seas appeared to be due to the presence of FYI throughout the study area, with the winter seasonal variation in the FYI SIC distribution being stronger (the distribution flattened/widened) than the MYI one.

\subsection{Comparison with NSIDC/CDR Sea Ice Concentration}

We compared our monthly IS-2 SIC estimates with the NSIDC/CDR SIC product. The CDR product is the daily SIC of the Arctic and the data coverage is different every day. The data are accumulated and averaged and are finally integrated into the monthly SIC. The grid has 304 columns and 448 rows. The grid values from 1 to 250 were retained and normalized to $0 \sim 1$. The values that were outside of this range, such 251,252 , were filtered out because these are fill values and represent other land cover types, such as land, lakes, etc. The spatial distribution of the SIC bias determined using the NSIDC/CDR and ICESat-2 data is shown in Figures 9-11.

The Chukchi Sea and the East Siberian Sea are close to $70^{\circ} \mathrm{N}$ and the Laptev Sea is located at about $80^{\circ} \mathrm{N}$, so $70^{\circ} \mathrm{N}$ and $80^{\circ} \mathrm{N}$ were taken as the cut-off points and the Arctic region was divided into areas with a high SIC in high latitude regions $\left(80^{\circ} \sim 90^{\circ} \mathrm{N}\right)$ and areas with a low SIC in mid-latitude regions $\left(70^{\circ} \sim 80^{\circ} \mathrm{N}\right)$. The bias of the SIC estimated determined by ATLAS and SSMIS at different latitudes were compared and analyzed. The consistency of Arctic region data and other remote sensing data can be further verified and analyzed through comparison and bias, the RMSE and the correlation coefficient. The full comparison statistics for the correlation coefficient (r), mean bias and standard deviation for January-December are shown in Figures 12 and 13.
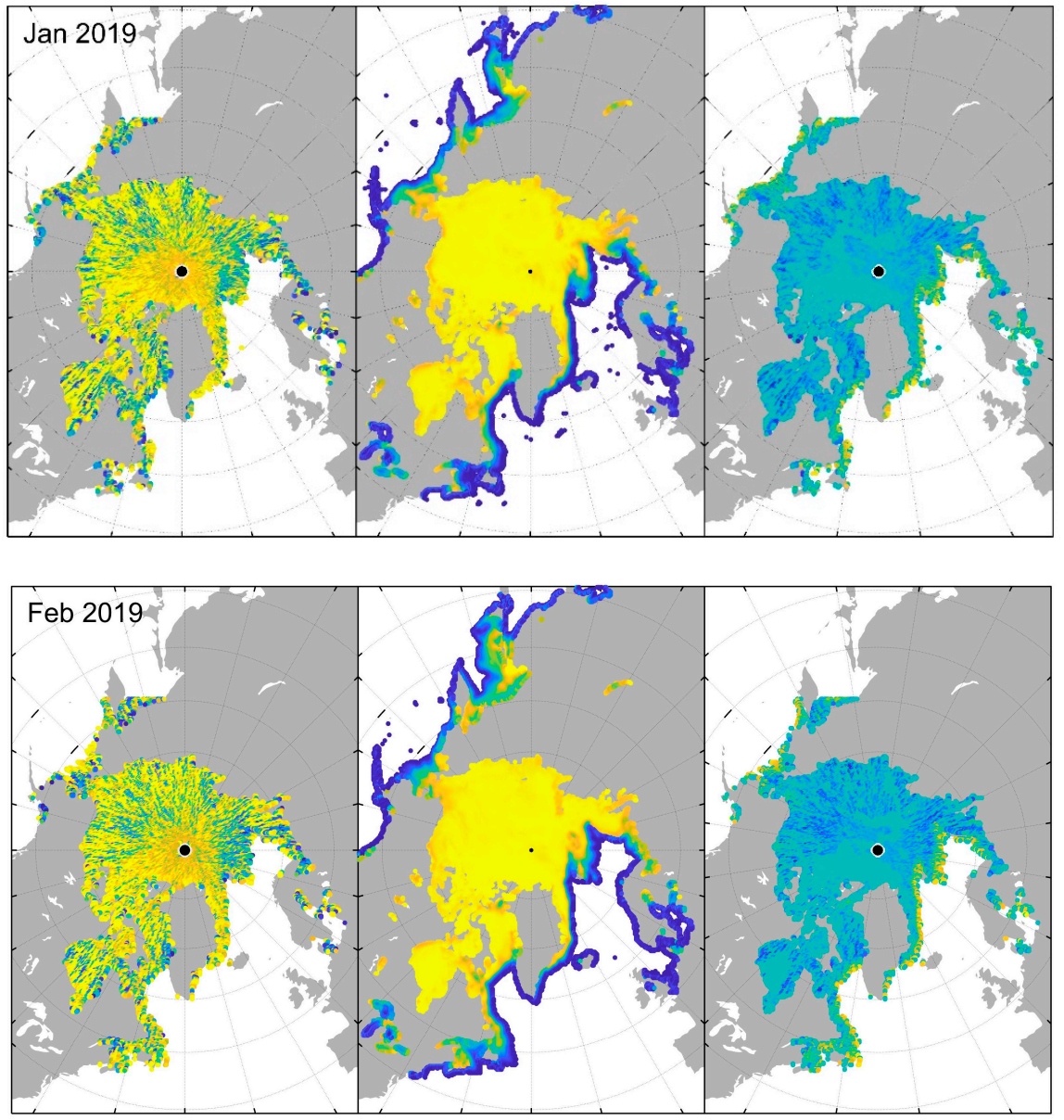

Figure 9. Cont. 

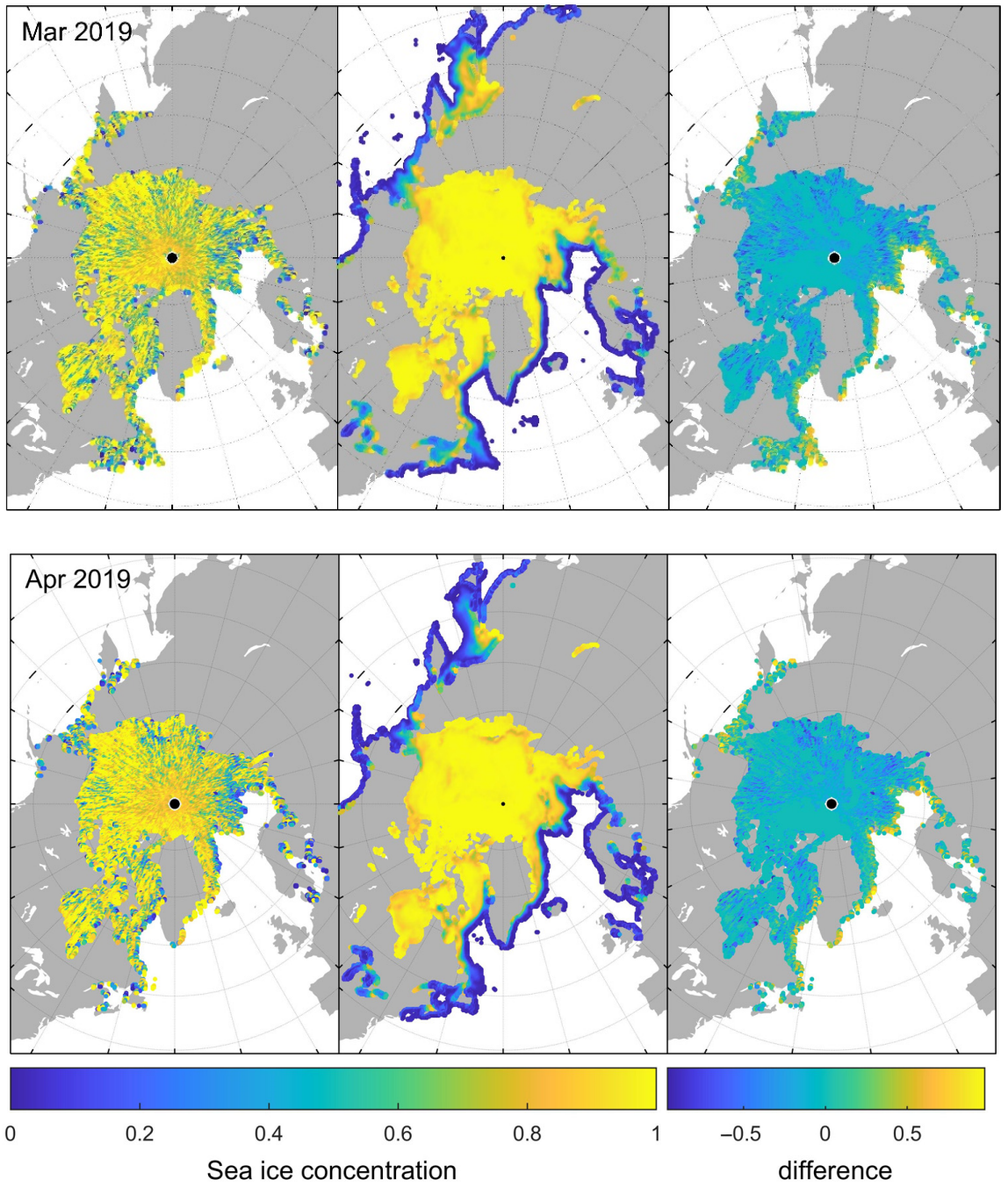

Figure 9. Comparisons of the gridded 2019 IS2 SIC data with NASA NSIDC/CDR SIC: (Left) ICESat2 SIC; (Middle) NSIDC/CDR SIC; (Right) ICESat-2 SIC minus NSIDC/CDR SIC for the period between January and April 2019.

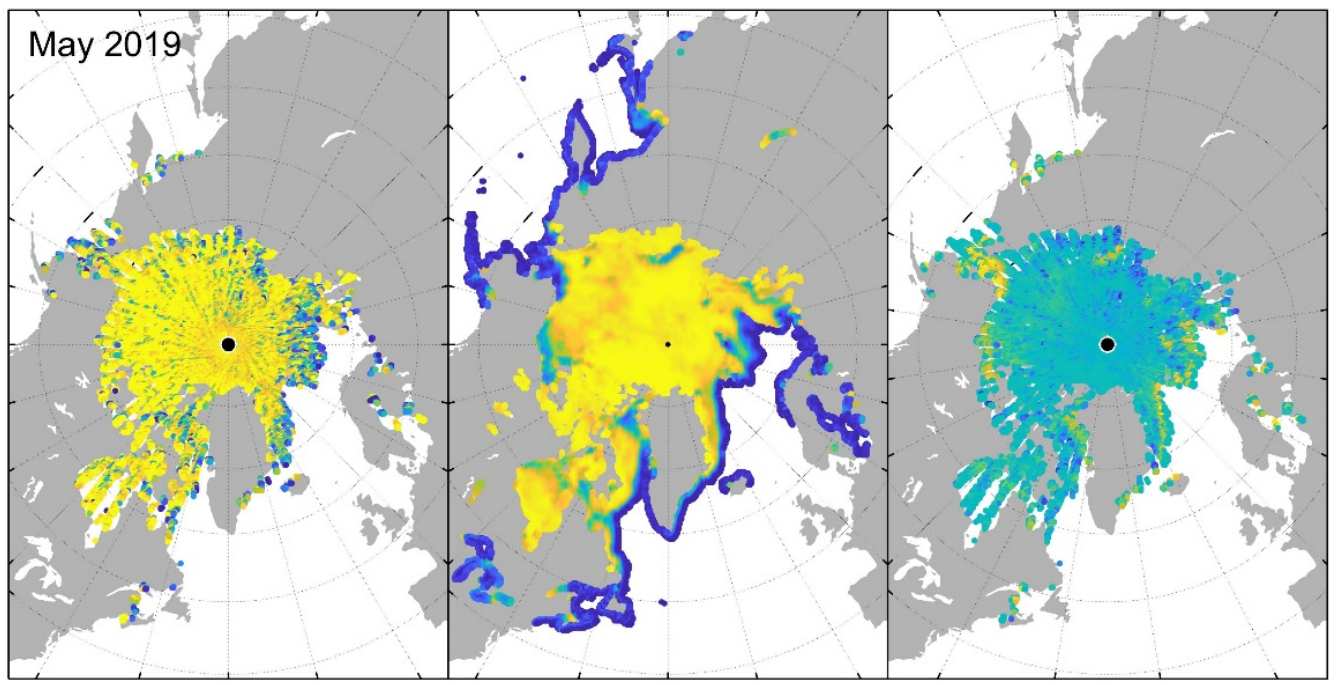

Figure 10. Cont. 

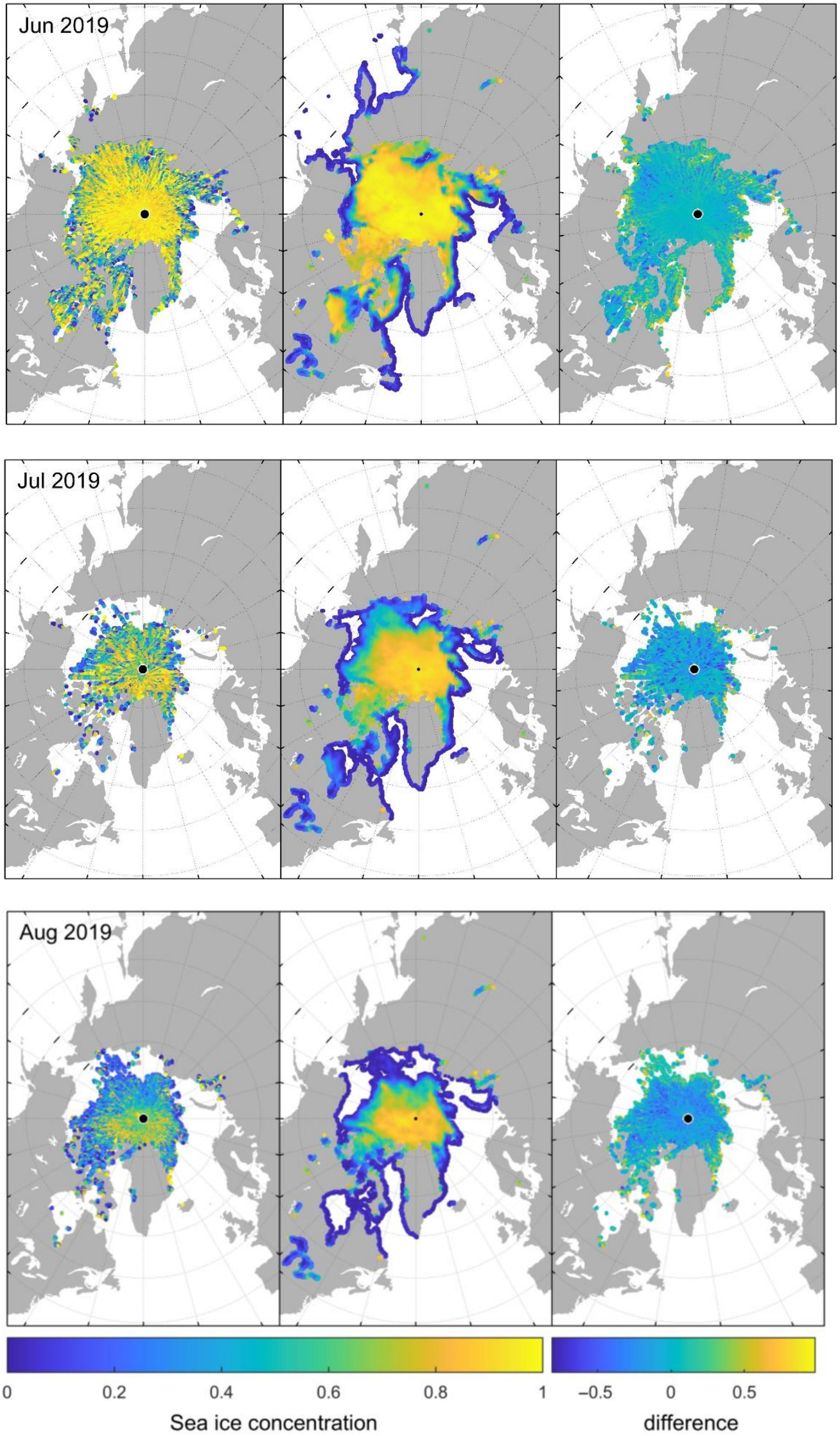

Figure 10. Same as Figure 9: (Left) ICESat-2 SIC; (Middle) NSIDC/CDR SIC; (Right) ICESat-2 SIC minus NSIDC/CDR SIC for the period between May and August 2019. 

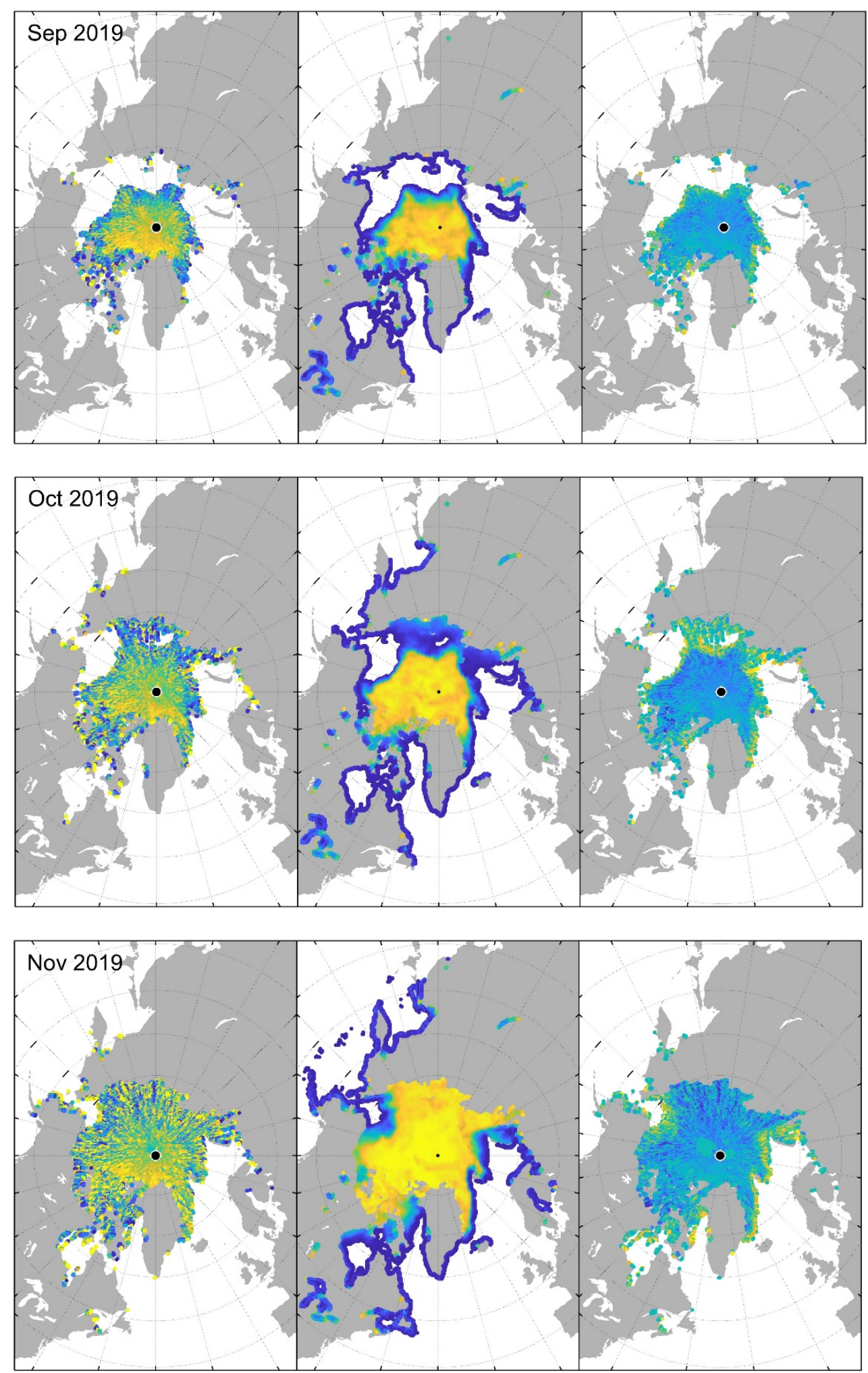

Figure 11. Cont. 


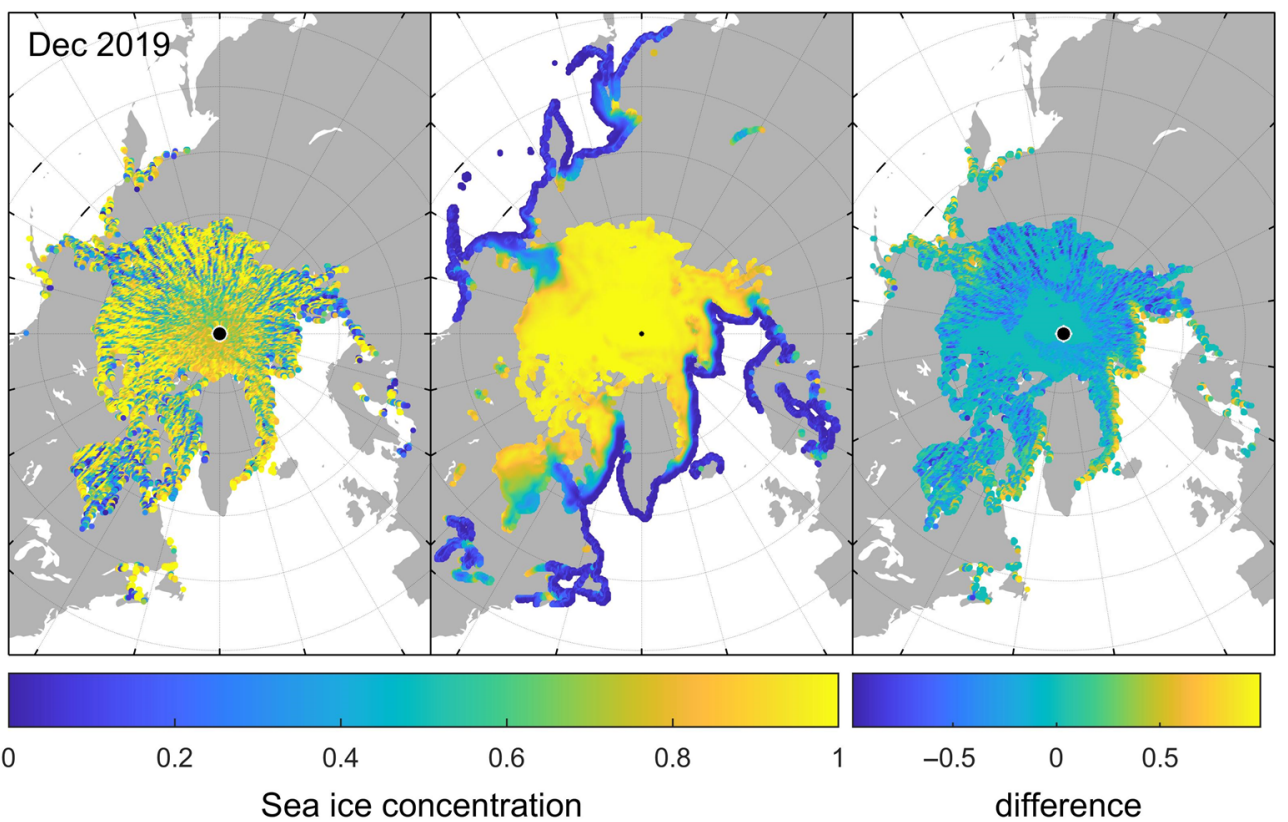

Figure 11. Same as Figure 9: (Left) ICESat-2 SIC; (Middle) NSIDC/CDR SIC; (Right) ICESat-2 SIC minus NSIDC/CDR SIC for the period between September and December 2019.

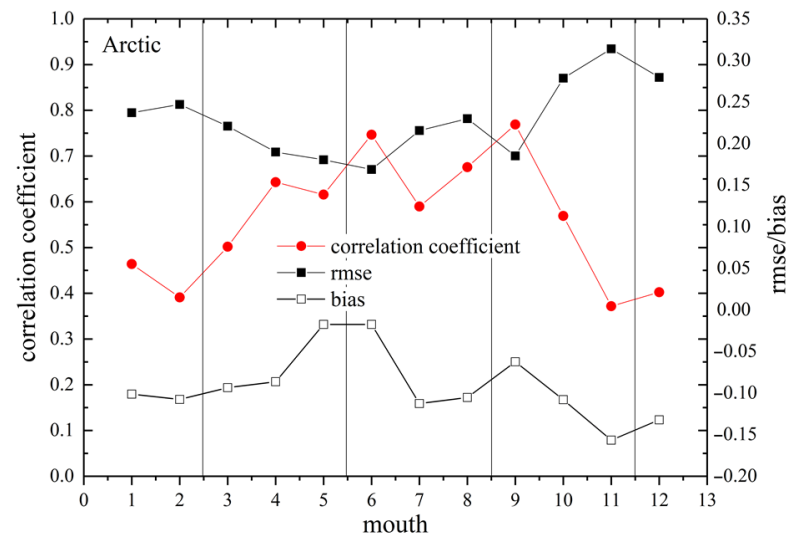

Figure 12. Variation curves of the correlation coefficient, mean bias and standard deviation between IS2 SIC and NSIDC/CDR SIC in Arctic from summer to autumn in 2019.

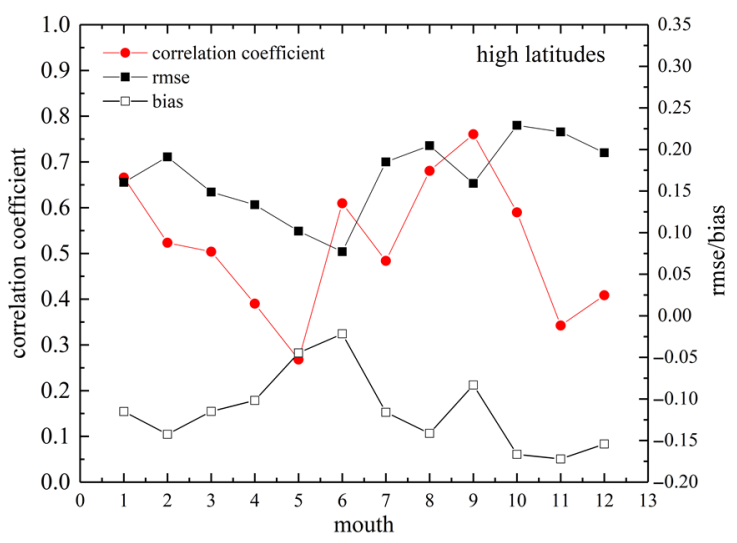

(a)

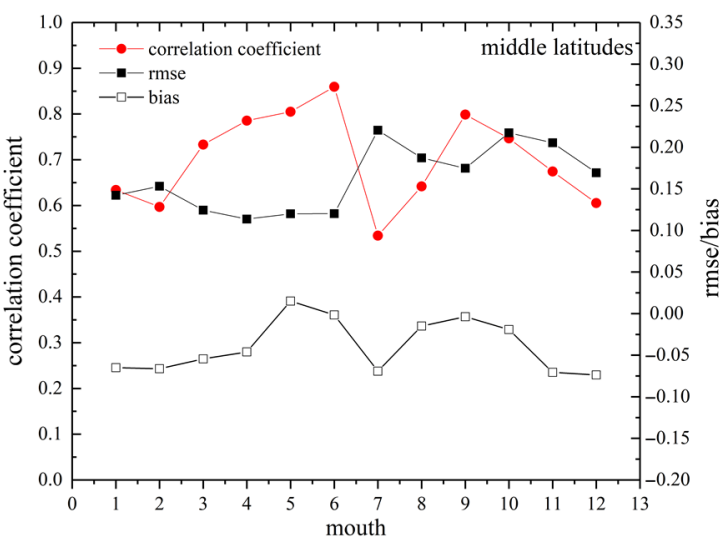

(b)

Figure 13. Variation curves of the correlation coefficient, mean bias and standard deviation between IS2 SIC and NSIDC/CDR SIC from summer to autumn in 2019: (a) high latitudes; (b) mid-latitudes. 
The correlation was between 0.37 and 0.77. Across the Arctic, the correlation was the highest in September $(r=0.7690)$ and the lowest in November $(r=0.3717)$. At high latitudes, the highest correlation was in September $(r=0.7604)$ and the lowest was in May $(\mathrm{r}=0.2681)$. At middle latitudes, the highest correlation was in June $(\mathrm{r}=0.8595)$ and the lowest correlation was in July $(\mathrm{r}=0.5340)$. In July, the IS-2 SIC coverage area was smaller than that of the NSIDC/CDR coverage area. This observational gap may result in a smaller sea ice coverage in July compared to August. With the exception of July 2019, the other IS-2 SIC maps showed good consistency in terms of the spatial distribution of the SIC. On the other hand, during summer in the Northern Hemisphere, which is in July, the sea ice that appears on a large number of melting pools influences the SIC estimations [33,39]. After the melting pool appears on the surface of the sea ice, its albedo, brightness, temperature and other characteristics are close to those of seawater and it is difficult to effectively distinguish the data obtained by microwave radiation sensors effectively. Therefore, it is easy to underestimate the SIC when calculating the sea ice coverage area in the grid [40].

When comparing the NSIDC/CDR SIC and SICCI (European Space Agency's climate change initiative sea ice project) products, it was found that the NSIDC product was better than the SICCI product in terms of reflecting the high-latitude and high-SIC regions, especially the regions near the North Pole. Analyzing the correlation coefficient between the IS-2 SIC and NSIDC/CDR SIC products enables a linear correlation in the Arctic region, but this is not enough to evaluate the product accuracy. The statistical results show that it is still effective to study the seasonal variation in the SIC using ATL10 and more work is needed to understand possible biases in the IS-2 data to increase our confidence in these findings.

The mean bias was $I_{I C E S a t-2}$ minus $I_{N S I D C}$, which is negative, meaning that $I_{I C E S a t-2}$ was less than $I_{N S I D C}$. The SIC bias decreased as the latitude increased and was negative at high latitudes. The mean bias south of $80^{\circ} \mathrm{N}$ was due to the different resolutions of individual islands, narrow channels and bays with different sea ice concentration inversion capabilities. In the Arctic region, the maximum bias was -0.1566 in November $(\mathrm{RMSE}=0.3139)$ and the minimum bias was -0.0174 in May (RMSE $=0.1805)$. In highlatitude regions, the maximum bias was -0.1722 in November (RMSE $=0.2211$ ) and the minimum bias was -0.0216 in June (RMSE $=0.0771)$. At mid-latitudes, the maximum bias was -0.0737 and the RMSE 0.1693 in December; the minimum bias was -0.0016 in June (RMSE= 0.1202). In spring (from March to June) and autumn (from September to November), the RMSE in the sea ice margin and inland region was larger and the bias was larger the closer it was to the region. In summer, the bias decreased to the minimum in June. The bias of highly concentrated regions was smaller than that of mid-latitude regions and the biases of the East Siberia, Laptev Sea and Kara Sea were larger. In winter, sea ice began to freeze rapidly and the biases of areas with high concentrations of ice cover decreased.

The bias and RMSE were small, probably because of the larger number of segments, so the estimated SIC was more accurate. The grids with a large bias and RMSE had the following characteristics: ice areas with small, dispersed water areas; low-concentration ice areas with more crushed ice; areas with blurred boundaries between ice and water; and areas where thick crushed ice and thinner melting ice coexisted. The reasons for the increases in the bias lay mainly in the fact that two products can have different inversion algorithms based on different principles in different frequencies bands as well as differences in the identification of melt pools and interglacial waterways with different spatial resolutions.

Different scholars have proposed different methods to classify ice and water via satellite altimetry. The authors of [41] used the pulse peak (PP) as a waveform classification index and distinguished the sea ice and interglacial channel by analyzing the echo waveform. Reference [42] took the lowest elevation point on the ICESat satellite track (the average of the lowest $2 \%$ of the difference between the observed height and the $50 \mathrm{~km}$ mean height) as the elevation of the interglacial channel. The authors of [43] used a Gaussian model to fit the echo waveform and based on the original PP index of the CryoSat-2 data and the pulse-cumulative standard deviation (CSD) index was added to identify the interglacial channels. Reference [44] used the least-squares configuration adjustment method 
to select the lowest elevation point within a certain range as the sea level to distinguish sea ice from seawater. For the ICESat-2 mission, Reference [26] studied the ice-water discrimination by analyzing variables such as the background photon rate, surface photon rate, solar altitude angle and surface roughness. The authors of [45] distinguished sea ice from seawater based on the necessary surface reflectivity and waveform parameters. Other methods for distinguishing sea ice from seawater have also been established [46,47].

The concentration comparisons demonstrate that the spatial distribution range of the SIC in different seasons was consistent. The SIC increased with latitude. The regions with extreme values were largely consistent. Although the locations of areas with the highest SIC are all located in offshore waters at high latitudes, there were differences; the largest differences typically occurred near the ice edge and sea-land boundary. The main advantage of the IS-2 process seems to be a more precise estimation of the boundaries of different ice concentration zones. For example, there was no sea ice in summer near the Arctic continent at $68^{\circ}, 80^{\circ}$ and $93^{\circ} \mathrm{N}$ and floating discrete sea ice was determined via IS- 2 measurements.

\subsection{SIC Obtained from Weak Beams and ICESat-2 Sea Ice Thickness Product ATL07}

The beams within each pair have different transmit energies ("weak" and "strong", with an energy ratio between them of approximately 1:4). The weak-beam segments are longer than the strong-beam segments. We also applied this method to the weak beams and analyzed what the SIC differences between strong and weak beams were. The SIC that was obtained from three weak beams in September is shown in Figure 14d. Compared to the NSIDC/CDR SIC data, the correlation coefficient was 0.7850 in the Arctic, 0.7702 at high latitudes and 0.8148 at mid-latitudes. The correlation coefficients estimated by weak ATL10 beams were higher than those estimated by strong ATL10 beams. The consistency of the strong ATL10 beams, weak ATL10 beams and NSIDC/CDR SIC could be further verified and analyzed by comparing deviation, standard deviation and correlation coefficient. The relevant evaluation indexes are shown in Table 3. We note that a more detailed assessment exploring weak-beam SIC products is needed, so we view this as an initial comparison rather than a complete validation analysis.

Stricter data selection criteria were applied to ATL10 for the freeboard calculations compared to ATL07, such as freeboards only being calculated when the SIC >50\%, when the height of the samples was at least $50 \mathrm{~km}$ away from the coast and when the $10 \mathrm{~km}$ segments contained a local sea surface reference [29]. This means that, in regions outside these criteria in ATL10, the surface types that were still valid and available from ATL07 could be used to calculate SIC. We used strong ATL07 beams to obtain the SIC (show in Figure 14b). Compared to the NSIDC/CDR SIC data, the correlation coefficient was 0.7498 in the Arctic, 0.7530 at high latitudes and 0.7743 at mid-latitudes. The three correlation coefficients were lower than those estimated by the strong ATL10 beams. This is possibly due to the ATL07 data being affected by tides and waves (Algorithm Theoretical Basis Document). However, the difference was not obvious. ATL07 was also a suitable data choice for SIC calculation. The relevant evaluation indexes are shown in Table 3.

Table 3. Correlation coefficient, deviation and standard deviation of strong ICESat-2 ATL07 beams, strong ATL10 beams, weak ATL10 beams and NSIDC/CDR SIC at a sea ice concentration with a 25 $\mathrm{km}$ spatial resolution were evaluated.

\begin{tabular}{cccccccccc}
\hline & \multicolumn{3}{c}{ Correlation Coefficient (r) } & \multicolumn{2}{c}{ Standard Deviation (RMSE) } & \multicolumn{2}{c}{ Mean Bias } \\
\hline Sep. & Arctic & $\begin{array}{c}\text { High } \\
\text { Latitude }\end{array}$ & $\begin{array}{c}\text { Middle } \\
\text { Latitude }\end{array}$ & Arctic & $\begin{array}{c}\text { High } \\
\text { Latitude }\end{array}$ & $\begin{array}{c}\text { Middle } \\
\text { Latitude }\end{array}$ & $\begin{array}{c}\text { Arctic } \\
\text { High } \\
\text { Latitude }\end{array} \begin{array}{c}\text { Middle } \\
\text { Latitude }\end{array}$ \\
\hline ATL07 strong beams & 0.7498 & 0.7530 & 0.7743 & 0.1865 & 0.1658 & 0.1766 & -0.0710 & -0.0906 & -0.0029 \\
ATL10 strong beams & 0.7647 & 0.7552 & 0.7958 & 0.1848 & 0.1593 & 0.1748 & -0.0617 & -0.0833 & -0.0019 \\
ATL10 weak beams & 0.7850 & 0.7702 & 0.8148 & 0.1652 & 0.1359 & 0.1674 & -0.0162 & -0.0344 & 0.0203 \\
\hline
\end{tabular}




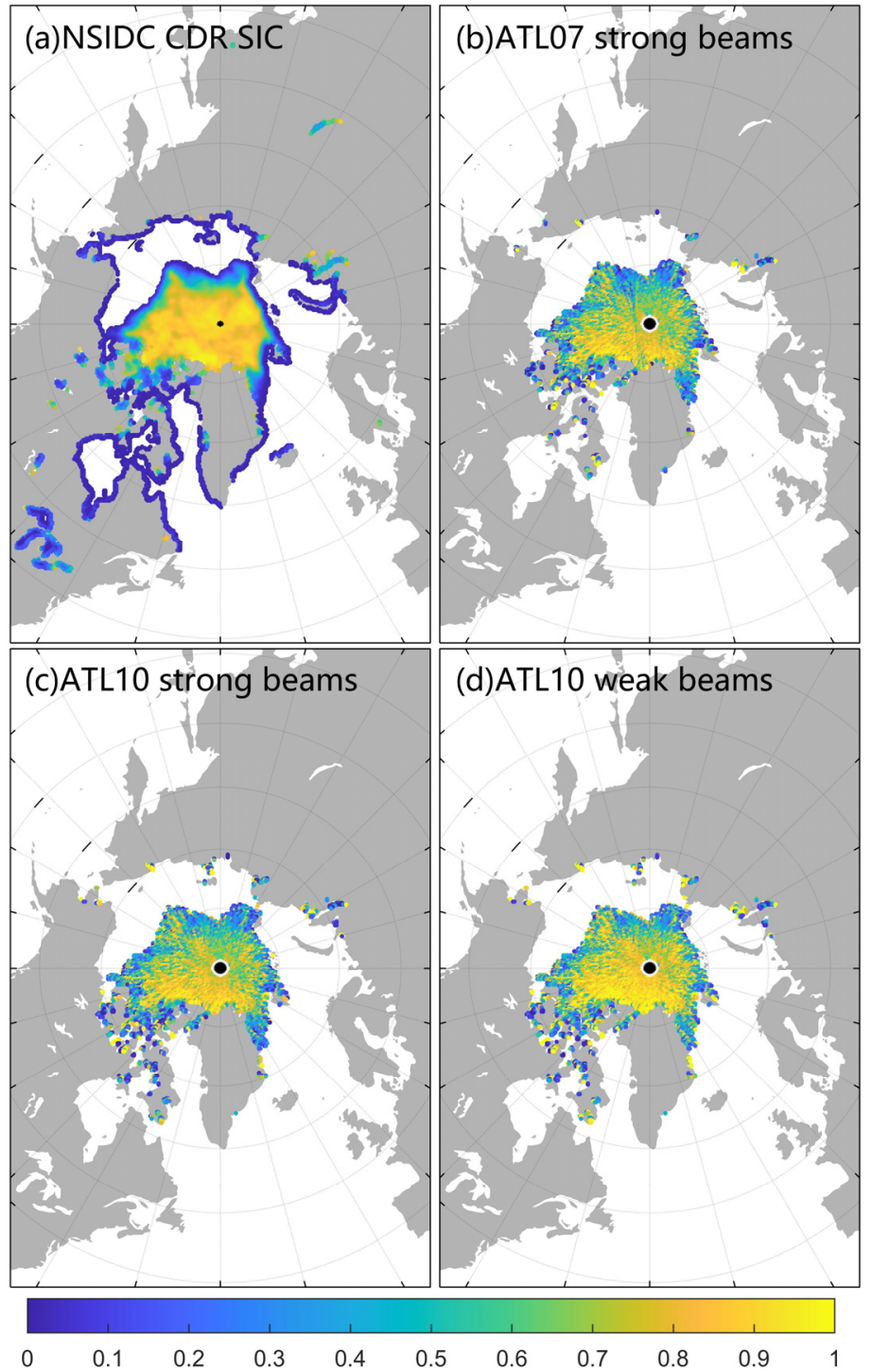

Figure 14. The SIC in September obtained from (a) NSIDC CDR; (b) ATL07 strong beams; (c) ATL10 strong beams; (d) ATL10 weak beams.

\section{Summary and Outlook}

In this study, we present our new processing chain for converting the official alongtrack ICESat-2 sea ice freeboard product (ATL10) into the SIC in the Arctic region using data from the year 2019. The along-track SIC is the ratio of the area covered by sea ice segments to the area of all of the along-track segments, which is assumed to be equal to the SIC of the grid. The coverage area of a segment is the area of a circle with a diameter that is the same as the segment length. If there were no segments in the grid, then we did not calculate the SIC for that grid. We only used strong beams in this initial effort, but there was good consistency across the strong beams in terms of our regional sea ice concentration distribution.

After analyzing the full year 2019 for the entire Arctic region, we found that the sea ice concentration that could be obtained with our method was in good agreement with the NSIDC/CDR SIC dataset. The results show that the SIC trends and the sea ice extent were consistent and that the IS-2 SIC was generally less than the CDR. Subsequently, the relevant factors between these differences were analyzed and the differences between them were counted. The comparisons showed moderate/strong correlations but biases of up to ten percent, depending on the month or NSIDC/CDR SIC product that was analyzed. 
The results show that the algorithm that is proposed in this paper is feasible and effective. When comparing the ATLAS and SSMIS, more work needs to be carried out to understand possible IS-2 biases in order to increase our confidence in these findings.

The spatial distribution of the two kinds of data, obviously, had seasonal differences. The areas with large differences between spring and winter were largely concentrated at the edges of the thin ice area and the average deviation increased in winter. On this basis, the variation in the SIC according to latitude was calculated and analyzed. The comparison with the SSMIS data showed that there were less differences in the SIC in high-latitude regions and that the different SIC obtained by the two satellite monitoring techniques was affected by seasonality.

\subsection{Understanding the SIC Differences between ATLAS and SSMIS}

A potential cause of these SIC biases between ICESat-2 and SSMIS could be due to the difference in seawater classification methods. The ICESat-2 photon-counting Laser Altimeter detection method used to determine sea ice is more sensitive. In addition, the accuracy of the NASA sea ice estimation CDR algorithm is lower during spring than in autumn and decreases significantly in summer due to ice melt. There is a lot of new sea ice in November and the results obtained by this algorithm may be underestimated for sea areas with extensive new sea ice, such as ice rind and high-SIC areas. Another aspect is that different sea ice boundary location extraction methods are used. Most of researchers in China and abroad use a 15\% concentration as a threshold to distinguish ice-bearing and ice-free areas, while some studies have used other thresholds, such as $20 \%$ [48]. It is also worth recognizing that satellites have different orbit cycles and thus represent different profiles across the Arctic Ocean, although the relatively high monthly coverage in both products should mitigate this possible issue.

Therefore, due to the influence of the factors mentioned for the two different datasets mentioned above, the NSIDC/CDR SIC may be higher than the ICESat-2 SIC, overall. Providing a more accurate sea ice area can mitigate these issues. The advantages of highresolution satellite remote-sensing concentration data are not only in the resolution, but also in their more accurate SIC inversion.

\subsection{Future Work}

A quantitative verification of the results using ground experimental data would make them more effective for determining the SIC algorithm evaluation from ICESat-2 ATL10 data. This would allow us to deepen the analysis mechanism of the relevant influencing factors and to study the complementarity of the algorithms. The complementarity of the two kinds of satellite monitoring technologies combined should be studied to determine the SIC method. One next step would be to extend the analysis to cover more years with smaller grid sizes to confirm the results of our case study with a larger amount of data.

The changes in the SIC in key areas of the Arctic shipping channel have a significant impact on the navigation safety of merchant ships in the navigation window. The existing SIC data cannot fully meet the needs of shipping safety and the demand for relevant realtime and high-precision sea ice data still exists. Due to the objective existence of various sea ice data, there are great differences among different products. How to scientifically analyze the influence of different factors on product accuracy, integrate multi-source fusion data, improve the reliability and real-time performance of remote sensing sea ice services and improve the inversion results of relevant models are important directions for sea ice research in the future.

Author Contributions: J.L., H.X. and Y.G. conceived the study, designed the experiments and edited the manuscript. X.T. and P.L. contributed to the analyses and discussion. All authors contributed significantly and participated sufficiently to take responsibility for this research study. All authors are in agreement with the submitted and accepted versions of the publication. All authors have read and agreed to the published version of the manuscript. 
Funding: The work described in the paper was substantially supported by the National Natural Science Foundation of China (Project No. 41822106), National Key Research and Development Program of China under Grant 2017YFA0603100, Dawn Scholar of Shanghai (Project No. 18SG22), State Key Laboratory of Disaster Reduction in Civil Engineering (Project No. SLDRCE19-B-35) and Fundamental Research Funds for the Central Universities of China.

Institutional Review Board Statement: Not applicable.

Informed Consent Statement: Not applicable.

Data Availability Statement: The ICESat-2 ATL10 sea ice freeboard data (Release 003) can be obtained from NSIDC (https:/ /nsidc.org/data/ATL10/versions/3, accessed on 1 December 2021). Daily and monthly NASA Climate Data Record (CDR) version 4 ice concentration data were obtained from NSIDC (https:/ /nsidc.org/data/G02202/versions/4, accessed on 1 December 2021).

Conflicts of Interest: The authors declare no conflict of interest.

\section{References}

1. Parkinson, C.L.; Cavalieri, D.J.; Gloersen, P.; Zwally, H.J.; Comiso, J.C. Arctic Sea ice extents, areas, and trends, $1978-1996$. J. Geophys. Res. Oceans 1999, 104, 20837-20856. [CrossRef]

2. Cohen, J.; Screen, J.A.; Furtado, J.C.; Barlow, M.; Whittleston, D.; Coumou, D.; Francis, J.; Dethloff, K.; Entekhabi, D.; Overland, J.; et al. Recent Arctic amplification and extreme mid-latitude weather. Nat. Geosci. 2014, 7, 627-637. [CrossRef]

3. Vihma, T. Effects of Arctic Sea ice decline on weather and climate: A review. Surv. Geophys. 2014, 35, 1175-1214. [CrossRef]

4. Screen, J.A.; Francis, J.A. Contribution of sea-ice loss to Arctic amplification is regulated by Pacific Ocean decadal variability. Nat. Clim. Chang. 2016, 6, 856-860. [CrossRef]

5. Parkinson, C.L. A 40-y record reveals gradual Antarctic Sea ice increases followed by decreases at rates far exceeding the rates seen in the Arctic. Proc. Natl. Acad. Sci. USA 2019, 116, 14414-14423. [CrossRef]

6. Comiso, J.C.; Cavalieri, D.J.; Parkinson, C.L.; Gloersen, P. Passive microwave algorithms for sea ice concentration: A comparison of two techniques. Remote Sens. Environ. 1997, 60, 357-384. [CrossRef]

7. Cavalieri, D.J.; Markus, T.; Ivanoff, A.; Glick, E. Assessment of AMSR-E Antarctic Winter Sea-Ice Concentrations Using Aqua MODIS. IEEE Trans. Geosci. Remote Sens. 2010, 48, 3331-3339. [CrossRef]

8. Ye, Y.; Shokr, M.; Heygster, G.; Spreen, G. Improving multiyear sea ice concentration estimates with sea ice drift. Remote Sens. 2016, 8, 397. [CrossRef]

9. Meier, W.N.; Fetterer, F.; Savoie, M.; Mallory, S.; Duerr, R.; Stroeve, J. NOAA/NSIDC Climate Data Record of Passive Microwave Sea Ice Concentration, Version 3; National Snow and Ice Data Center (NSIDC): Boulder, CO, USA, 2017.

10. Karvonen, J. A sea ice concentration estimation algorithm utilizing radiometer and SAR data. Cryosphere 2014, 8, 1639-1650 [CrossRef]

11. Ivanova, N.; Johannessen, O.M.; Pedersen, L.T.; Tonboe, R.T. Retrieval of Arctic Sea Ice Parameters by Satellite Passive Microwave Sensors: A Comparison of Eleven Sea Ice Concentration Algorithms. Geosci. Remote Sens. 2014, 52, 7233-7246. [CrossRef]

12. Cavalieri, D.J.; Gloersen, P.; Campbell, W.J. Determination of sea ice parameters with the NIMBUS 7 SMMR. J. Geophys. Res. Atmos. 1984, 89, 5355-5369. [CrossRef]

13. Markus, T.; Cavalieri, D.J. An enhancement of the NASA Team sea ice algorithm. IEEE Trans. Geosci. Remote Sens. 2000, 38 , 1387-1398. [CrossRef]

14. Comiso, J.C.; Parkinson, C.L. Arctic sea ice parameters from AMSR-E data using two techniques and comparisons with sea ice from SSM/I. J. Geophys. Res. 2008, 113. [CrossRef]

15. Shokr, M.; Lambe, A.; Agnew, T. A new algorithm (ECICE) to estimate ice concentration from remote sensing observations: An application to 85-GHz passive microwave data. IEEE Trans. Geosci. Remote Sens. 2008, 46, 4104-4121. [CrossRef]

16. Ye, Y.; Heygster, G. Arctic multiyear ice concentration retrieval from SSM/I data using the NASA Team algorithm with dynamic tie points. In Towards an Interdisciplinary Approach in Earth System Science; Springer: Cham, Switzerland, 2015; pp. 99-108.

17. Ye, Y.; Heygster, G.; Shokr, M. Improving multiyear ice concentration estimates with reanalysis air temperatures. IEEE Trans. Geosci. Remote Sens. 2015, 54, 2602-2614. [CrossRef]

18. Kwok, R.; Comiso, J.C. The perennial ice cover of the Beaufort Sea from active-and passive-microwave observations. Ann. Glaciol 1997, 25, 376-381. [CrossRef]

19. Tonboe, R.T.; Eastwood, S.; Lavergne, T.; Sørensen, A.M.; Rathmann, N.; Dybkjær, G.; Pedersen, L.T.; Høyer, J.L.; Kern, S. The EUMETSAT sea ice concentration climate data record. Cryosphere 2016, 10, 2275-2290. [CrossRef]

20. Yang, Y.; DongChen, E.; Wang, H.; Chao, D.; Hwang, C.; Li, F.; Ai, S. Sea ice concentration over the Antarctic Ocean from satellite pulse altimetry. Sci. China Earth Sci. 2011, 54, 113-118. [CrossRef]

21. Gabarro, C.; Turiel, A.; Elosegui, P.; Pla-Resina, J.A.; Portabella, M. New methodology to estimate Arctic Sea ice concentration from SMOS combining brightness temperature differences in a maximum-likelihood estimator. Cryosphere 2017, 11, 1987-2002. [CrossRef] 
22. Petty, A.A.; Holland, M.M.; Bailey, D.A.; Kurtz, N.T. Warm Arctic, increased winter sea ice growth? Geophys. Res. Lett. 2018, 45, 12922-12930. [CrossRef]

23. Markus, T.; Neumann, T.; Martino, A.; Abdalati, W.; Brunt, K.; Csatho, B.; Farrell, S.; Fricker, H.; Gardner, A.; Harding, D.; et al. The Ice, Cloud, and land Elevation Satellite-2 (ICESat-2): Science requirements, concept, and implementation. Remote Sens. Environ. 2017, 190, 260-273. [CrossRef]

24. Parrish, C.E.; Magruder, L.A.; Neuenschwander, A.L.; Forfinski-Sarkozi, N.; Alonzo, M.; Jasinski, M. Validation of ICESat-2 ATLAS bathymetry and analysis of ATLAS's bathymetric mapping performance. Remote Sens. 2019, 11, 1634. [CrossRef]

25. Kwok, R.; Markus, T.; Kurtz, N.T.; Petty, A.A.; Neumann, T.A.; Farrell, S.L.; Cunningham, G.F.; Hancock, D.W.; Ivanoff, A.; Wimert, J.T. Surface height and sea ice freeboard of the Arctic Ocean from ICESat-2: Characteristics and early results. J. Geophys. Res. Ocean 2019, 124, 6942-6959. [CrossRef]

26. Kwok, R.; Cunningham, G.F.; Hoffmann, J.; Markus, T. Testing the ice-water discrimination and freeboard retrieval algorithms for the ICESat-2 mission. Remote Sens. Environ. 2016, 183, 13-25. [CrossRef]

27. Kwok, R.; Cunningham, G.; Markus, T.; Hancock, D.; Morison, J.H.; Palm, S.P.; Farrell, S.L.; Ivanoff, A.; Wimert, J. ATLAS/ICESat-2 L3A Sea Ice Height, Version 2; NSIDC, National Snow and Ice Data Center: Boulder, CO, USA, 2019. [CrossRef]

28. Kwok, R.; Cunningham, G.F.; Kacimi, S.; Webster, M.A.; Kurtz, N.T.; Petty, A.A. Decay of the snow cover over Arctic Sea ice from ICESat-2 acquisitions during summer melt in 2019. Geophys. Res. Lett. 2020, 47, e2020GL088209. [CrossRef]

29. Kwok, R.; Cunningham, G.F.; Hancock, D. 'ICESat-2 Algorithm Theoretical Basis Document for Sea Ice Products (ATL07 \& ATL10)'. 2019. Available online: https://icesat-2.gsfc.nasa.gov/sites/default/files/page_files/ICESat2_ATL07_ATL10_ATBD_r004.pdf (accessed on 1 December 2021).

30. Kwok, R.; Cunningham, G.; Hancock, D.; Ivanoff, A.; Wimert, J. Ice, Cloud, and Land Elevation Satellite (ICESat-2) Algorithm Theoretical Basis Document (ATBD) for Sea Ice Products; National Aeronautics and Space Administration: Washington, DC, USA; Goddard Space Flight Centre: Greenbelt, MD, USA, 2019.

31. Kwok, R.; Kacimi, S.; Markus, T.; Kurtz, N.T.; Studinger, M.; Sonntag, J.G.; Manizade, S.S.; Boisvert, L.N.; Harbeck, J.P. ICESat-2 surface height and sea ice freeboard assessed with ATM lidar acquisitions from Operation IceBridge. Geophys. Res. Lett. 2019, 46, 11228-11236. [CrossRef]

32. Peng, G.; Meier, W.N.; Scott, D.J.; Savoie, M.H. A long-term and reproducible passive microwave sea ice concentration data record for climate studies and monitoring. Earth Syst. Sci. Data 2013, 5, 311-318. [CrossRef]

33. Brucker, L.; Cavalieri, D.J.; Markus, T.; Ivanoff, A. NASA Team 2 Sea Ice Concentration Algorithm Retrieval Uncertainty. Geosci. Remote Sens. 2014, 52, 7336-7352. [CrossRef]

34. Kwok, R. Sea ice convergence along the Arctic coasts of Greenland and the Canadian Arctic Archipelago: Variability and extremes (1992-2014). Geophys. Res. Lett. 2015, 42, 7598-7605. [CrossRef]

35. Petty, A.A.; Webster, M.; Boisvert, L.; Markus, T. The NASA Eulerian Snow on Sea Ice Model (NESOSIM) v1. 0: Initial model development and analysis. Geosci. Model Dev. 2018, 11, 4577-4602. [CrossRef]

36. Shokr, M.; Dabboor, M. Interannual variability of young ice in the arctic estimated between 2002 and 2009. IEEE Trans. Geosci. Remote Sens. 2013, 51, 3354-3370. [CrossRef]

37. Krishfield, R.A.; Proshutinsky, A.; Tateyama, K.; Williams, W.J.; Carmack, E.C.; McLaughlin, F.A.; Timmermans, M.L. Deterioration of perennial sea ice in the Beaufort Gyre from 2003 to 2012 and its impact on the oceanic freshwater cycle. J. Geophys. Res. Ocean 2014, 119, 1271-1305. [CrossRef]

38. Petty, A.A.; Hutchings, J.K.; Richter-Menge, J.A.; Tschudi, M.A. Sea ice circulation around the Beaufort Gyre: The changing role of wind forcing and the sea ice state. J. Geophys. Res. Ocean 2016, 121, 3278-3296. [CrossRef]

39. Kern, S.; Rösel, A.; Pedersen, L.T.; Ivanova, N.; Saldo, R.; Tonboe, R.T. The impact of melt ponds on summertime microwave brightness temperatures and sea-ice concentrations. Cryosphere 2016, 10, 2217-2239. [CrossRef]

40. Meier, W.N.; Stewart, J.S. Assessing uncertainties in sea ice extent climate indicators. Environ. Res. Lett. $2019,14,035005$. [CrossRef]

41. Laxon, S. Sea ice altimeter processing scheme at the EODC. Int. J. Remote Sens. 1994, 15, 915-924. [CrossRef]

42. Zwally, H.J.; Yi, D.; Kwok, R.; Zhao, Y. ICESat measurements of sea ice freeboard and estimates of sea ice thickness in the Weddell Sea. J. Geophys. Res. Ocean 2008, 113. [CrossRef]

43. Laxon, S.W.; Giles, K.A.; Ridout, A.L.; Wingham, D.J.; Willatt, R.; Cullen, R.; Kwok, R.; Schweiger, A.; Zhang, J.; Haas, C.; et al. CryoSat-2 estimates of Arctic Sea ice thickness and volume. Geophys. Res. Lett. 2013, 40, 732-737. [CrossRef]

44. Forsberg, R.; Skourup, H. Arctic Ocean gravity, geoid and sea-ice freeboard heights from ICESat and GRACE. Geophys. Res. Lett. 2005, 32, 21. [CrossRef]

45. Farrell, S.L.; Laxon, S.W.; Mcadoo, D.C.; Yi, D.; Zwally, H.J. Five years of arctic sea ice freeboard measurements from the ice, cloud and land elevation satellite. J. Geophys. Res. Ocean 2009, 114. [CrossRef]

46. Petty, A.A.; Kurtz, N.T.; Kwok, R.; Markus, T.; Neumann, T.A. Winter Arctic Sea ice thickness from ICESat-2 freeboards. J. Geophys. Res. Ocean 2020, 125, e2019JC015764. [CrossRef]

47. Kacimi, S.; Kwok, R. The Antarctic Sea ice cover from ICESat-2 and CryoSat-2: Freeboard, snow depth, and ice thickness. Cryosphere 2020, 14, 4453-4474. [CrossRef]

48. Pang, X.; Pu, J.; Zhao, X.; Ji, Q.; Qu, M.; Cheng, Z. Comparison between AMSR2 sea ice concentration products and pseudo-ship observations of the Arctic and Antarctic sea ice edge on cloud-free days. Remote Sens. 2018, 10, 317. [CrossRef] 